\title{
When Power Plants Leave Town: Environmental Quality and the Housing Market in China
}

\author{
Guoying Deng ${ }^{1} \cdot$ Manuel A. Hernandez ${ }^{2} \mathbb{D} \cdot$ Shu $\mathrm{Xu}^{3}$
}

Accepted: 14 October 2020 / Published online: 24 October 2020

(c) The Author(s) 2020

\begin{abstract}
Air pollution is a major environmental issue in China. This paper exploits the relocation of two major power plants in a large Chinese city as a quasi-natural experiment to examine the effect of changes in the quality of the environment on the housing market. We use an extensive transaction dataset of new apartment units in the affected and neighboring areas. We find that the plants' closure is associated with a $12-14 \%$ increase in prices and $13-31 \%$ rise in the volume of transactions in neighborhoods within five kilometers of the plants. We further observe a higher change in prices among more expensive houses. The estimated monthly aggregate effect of the closures on the local housing market is over 50 million US dollars during the first 2 years after the relocations.
\end{abstract}

Keywords Power plants $\cdot$ Environmental quality $\cdot$ Housing market $\cdot$ China

JEL Classification Q53 - Q51 · R30

\begin{abstract}
We thank the valuable comments of seminar participants at the American Economic Association Annual Meeting, Latin American Meeting of the Econometric Society, Asian Meeting of the Econometric Society, Triennial Congress of the International Economic Association and European Economic Association Annual Meeting. We also thank Klaus Moeltner and two anonymous referees for their many useful comments. The authors gratefully acknowledge financial support from the Private Enterprise Research Center (PERC) of Texas A\&M University, Fundamental Research Funds for the Central Universities of Sichuan University (SKQY201624), Youth Outstanding Talent Training Program of Sichuan University (SKSYL201812 and 2019hhf-08) and National Natural Science Foundation of China (71773081).
\end{abstract}

Electronic supplementary material The online version of this article (https://doi.org/10.1007/s1064 0-020-00517-x) contains supplementary material, which is available to authorized users.

Manuel A. Hernandez

m.a.hernandez@cgiar.org

Guoying Deng

dengguoying@scu.edu.cn

Shu Xu

xushu@swufe.edu.cn

1 Sichuan University, Chengdu, China

2 IFPRI, 1201 Eye Street NW, Washington, DC 20005, USA

3 Southwestern University of Finance and Economics, Chengdu, China 


\section{Introduction}

Air pollution in China has reached critical levels in recent years, representing a major health and environmental concern across most urban areas in the country. According to the Ambient Air Pollution report released by the World Health Organization (WHO) in 2016, China is among the most polluted countries in the world with annual average concentrations of fine particulate matter (PM) four to five times higher than the levels recommended by the WHO in their Air Quality Guidelines. ${ }^{1}$ Respiratory and heart diseases related to ambient air pollution are, in turn, the leading cause of death in China. As a consequence, there is an ongoing debate in academic and policy forums on how to reduce pollution problems, including implementing more stringent environmental regulatory schemes and promoting the use of more energy-efficient and less polluting production technologies.

Several action plans have also been put in place across China over the past years for reducing air pollution. ${ }^{2}$ Particular attention has been given to the closing and relocation of coal-fired power plants in urban areas, which constitute a major source of pollution in a setting where there is a continuous growing demand for energy and where most of the energy production is highly coal-dependent. The IEA Clean Coal Center indicates that 620 of the over 2300 coal-fired power stations in the world are located in China. ${ }^{3}$ In addition, coalbased power generation in China is expected to account for $65-70 \%$ of the total energy generation in the upcoming decades. ${ }^{4}$

This paper uses the relocation of two major coal power plants in a large city in China as a quasi-natural experiment to assess the effect of changes in the quality of the environment on the local housing market. We base our analysis on an extensive daily transaction dataset of new apartment units purchased before and after the closing of the plants. The dataset includes all new apartment purchases made during the period of analysis (January 2005 through May 2009) in the downtown area, registered through the corresponding Housing Authority of the city. We follow a hedonic approach and perform difference-in-differences (DID) and change-in-changes (CIC) estimations to compare the change in housing prices and volume of transactions in the affected and neighboring areas. If consumers value the environmental quality of the neighborhood where they plan to reside, we should expect both an increase in the prices and number of house constructions (purchases) in the vicinity of the plants. Similarly, individuals placing a higher value on the quality of the environment will likely be more willing to live in these areas, encouraging also developers to increase the housing supply (and available amenities and features) in these locations. ${ }^{5}$

\footnotetext{
${ }^{1}$ Fine particular matter refers to particles found in the air, which include dust, dirt, liquid droplets, soot and smoke. These substances are associated with a broad spectrum of acute and chronic illness, such as lung cancer, chronic obstructive pulmonary disease, and cardiovascular diseases.

2 See eg., Lin and Elder (2014) for additional details on the Air Pollution Prevention and Control Action Plan issued by the State Council in September 2013.

3 www.worldcoal.org.

4 The World Bank, https://go.worldbank.org/C1DZDI9XM0.

5 Since we are interested on estimating the causal effect of the plants' relocations on the market price of new apartment units, a potential change in the composition of buyers in the affected areas (with varying airquality preferences) need not necessarily represent a bias; it is just a channel through which the causal effect operates. In the empirical section we discuss the observed variation in socioeconomic (and hedonic) characteristics between the treatment and control areas, although formally testing for taste-based sorting is beyond the objective of our paper due to the lack of a wider set of (time-varying) neighborhood demographic indicators over the short period of study.
} 
The estimation results show that the closure of the power plants is associated with a positive and significant short-term increase in the price of new apartment units and the volume of transactions. We find that the price per square meter of new apartments located within five kilometers of the plants increased by $12-14 \%$, while the volume of weekly transactions increased by $13-31 \%$. We also observe that more expensive units exhibited a higher increase in prices. Additional robustness checks support the positive impact of the relocations on the local housing market, including a larger impact when considering areas closer to the plants and the opposite for areas farther away. On aggregate, the relocation events resulted in an additional 52 million US dollars per month in the market for new apartments over the first two years following the plants' closures.

Our study contributes to the empirical literature that uses hedonic methods to examine the impact of environmental disamenities on the housing market. Recent studies include Chay and Greenstone (2005), Greenstone and Gallagher (2008), Bayer et al. (2009), Davis (2011), Hodge (2011), Gamper-Rabindran and Timmins (2013) and Muehlenbachs et al. (2015), all focused in the US. These studies generally rely on quasiexperimental methods to develop a valid counterfactual and assess the effect of the disamenity on the locations under analysis, with mixed results.

Chay and Greenstone (2005) exploit the structure of the Clean Air Act amendments, which identified attainment and nonattainment pollution-concentration counties, and show a negative effect of total suspended particulates (TSPs) on housing prices using 1970-1980 county-level data. Greenstone and Gallagher (2008) find that Superfund cleanups of hazardous waste have a very limited impact on the housing market; the authors compare the evolution of different market outcomes over 1980-2000 between areas (census-tracts) surrounding the waste sites first chosen for cleanups and the areas surrounding the sites that narrowly missed qualifying for the cleanups. Yet, Gamper-Rabindran and Timmins (2013) show that Greenstone and Gallagher's modest effects may be driven by spatial aggregation bias resulting from their use of Census tract means; these authors rely on panel data methods and show that cleanup leads to an increase in tract-level housing values and there is a larger price appreciation at the lower percentiles of the within-tract house value distribution. Bayer et al. (2009) find a negative effect of particulate matter concentration on housing prices in metropolitan areas between 1990 and 2000, using pollution from distance sources as an instrument for local pollution and accounting for mobility costs between areas. Muehlenbachs et al. (2015) analyze the effect of shale gas development on property values in New York and Pennsylvania using alternative difference-in-differences approaches and find large negative effects on nearby groundwater-dependent homes and small positive effects on piped-water-dependent homes.

Closer to our study, Davis (2011) evaluate the effect of power plants' openings on local housing values and rents between 1993 and 2000. The analysis is based on microdata from a disaggregated version of the US decennial census for the years 1990 and 2000, which permits to identify households at the Census block level and control for specific local characteristics prior to the plants' openings. Propensity score weighting is further used given that power plants in the US are generally opened in low population density areas, with housing and demographic characteristics that differ from the rest of the country. The author finds modest declines in housing values and rents in the neighborhoods where a power plant is opened, as well as a small change in the local welfare compared to, for example, the cost of constructing a new plant. Hodge (2011), in turn, examines the effect of ethanol plants on residential property values in two communities in Michigan using available sales data for the period 1999-2009, obtained from two multiple listing services in the state. The 
author performs separate estimations by community and shows a significant decrease in house prices after the plants began operations in the areas. ${ }^{6}$

The study also contributes to the continuous discussion in China regarding the potential benefits of relocating and siting new power plants away from high-population-density urban areas, which have an increasing demand for energy and an urgent need to decrease pollution levels to acceptable measures. Most of the previous studies have mainly adopted a more general discussion on the topic using aggregate indicators, including Cai et al. (2008), Tu (2008), Chen (2009) and Lin and Liu (2010). ${ }^{7}$ Two exceptions are Jim and Chen (2007) and Zheng and Kahn (2008). The former find that consumers place a high value on the quality of the outdoor environment based on a survey to homebuyers in Guangzhou; the latter estimate home price hedonic gradients in Beijing using transaction data and find a significant positive correlation between air quality and house prices. ${ }^{8}$

The dataset used in the analysis allow us to exclusively concentrate on variations in prices and volume of transactions of relatively homogenous apartment units located in comparable, neighboring downtown areas, recognizing that the (unobserved) type of buyers searching for a new house may differ both by location and building type; i.e., individuals searching for a house in the downtown area may be different than those preferring to live in the suburbs, while individuals searching for an apartment may be different than those looking for a townhome or single family unit. Likewise, working with actual transaction data avoids potential misreporting problems in house values, as opposed to studies that rely on Census data with self-reported information and house value ranges in some cases. ${ }^{9}$

The relatively short time frame of our study around the closing of the power plants also helps to reduce alternative explanations, other than the closing events, for the results obtained. We are not aware of any other major event or regulation change that occurred around the period of the study that could have affected housing prices in the downtown area. The analysis, however, still relies on a quasi-experimental approach comparing changes in market outcomes across adjacent areas such that we cannot completely rule out other possible explanations. Similarly, the estimated effects on the housing market may not be fully driven by an improvement in the environmental quality after the plants' closures and we discuss below other possible factors.

The remainder of the paper is organized as follows. Section 2 provides further details about the power plants operating in downtown Chengdu, the resulting pollution problems and their relocation. Section 3 describes the data and the methodology used in the analysis. Section 4 presents and discusses the estimation results and Sect. 5 concludes.

\footnotetext{
6 Prior studies that examine the effect of power plants on residential property values in the US include Blomquist (1974), Nelson (1981) and Gamble and Downing (1982). Blomquist (1974) find a negative impact of electric utility power plants on nearby housing values, while Nelson (1981) and Gamble and Downing (1982) do not find a statistically significant impact of nuclear power plants, including the 1979 meltdown accident in the Three Mile Island (TMI) plant in Pennsylvania, on surrounding residential property values.

7 These studies typically focus on the compatibility and implications of the intended reductions in the emission of pollutants and toxic residues with the predicted industrial and urban development of the country.

${ }^{8}$ Recent studies on more general effects of pollution in China include Chen et al. (2013), Viard and Fu (2015), Zhang et al. (2017), Barwick et al. (2018), Barwick et al. (2019) and Li et al. (2019).

9 Other studies that use housing transaction data include Davis (2004), Zheng and Kahn (2008), Abott and Klaiber (2011), Kuminoff and Pope (2014) and Barwick et al. (2019).
} 


\section{Background}

Chengdu is the capital of Sichuan Province and the largest sub-provincial city in Western China with about ten million residents. ${ }^{10}$ Like other major Chinese cities, Chengdu has been exposed to important levels of pollution in recent decades with consequent health and environmental problems. Based on the Ambient Air Pollution report from the WHO (2014), the annual mean concentration of fine particulate matter in Chengdu is around $102 \mu \mathrm{g} / \mathrm{m}^{3}$ for particles smaller than $10 \mu \mathrm{m}$ in diameter or microns (PM10) and $47 \mu \mathrm{g} /$ $\mathrm{m}^{3}$ for particles smaller than 2.5 microns (PM2.5). ${ }^{11}$ These air pollution levels are higher than the levels for 91 out of the 112 Chinese cities included in the report and significantly higher than the WHO Air Quality Guidelines annual mean values of $20 \mu \mathrm{g} / \mathrm{m}^{3}$ for PM10 and $10 \mu \mathrm{g} / \mathrm{m}^{3}$ for PM2.5. In terms of the air pollution index (or air quality index) tracked daily by China's Ministry of Environmental Protection, which accounts for additional air pollutants like sulfur dioxide $\left(\mathrm{SO}_{2}\right)$, nitrogen dioxide $\left(\mathrm{NO}_{2}\right)$, carbon monoxide $(\mathrm{CO})$ and ozone $\left(\mathrm{O}_{3}\right)$, Chengdu is one of the Chinese cities with the poorest air quality with air pollution levels considered unhealthy. ${ }^{12}$

As part of the plan to reduce outdoor pollution and improve air quality in Chengdu, the Eleventh Five-Year Plan of the city for the period 2006-2010, released in early 2006, identified thermal power plants, metallurgy, light industries (including leather, textile, paper making and food manufacturers) and chemical and pharmaceutical industries as the major industrial sources of pollution. ${ }^{13}$ The Plan paid particular attention to the coal thermal power plants operating in the downtown area and how to solve their waste problems. The plants had become a symbol of dirt, contamination and disorder in the area and were the major single source of pollution in the area, generating immense quantities of soot, dust and other toxic residues, and emitting large amounts of sulfur dioxide, nitrogen oxides, and some radioactive and heavy metals. ${ }^{14}$

As a result, in early 2006 the government of Chengdu decided to shut down and relocate outside of the city the two oldest plants operating in Chenghua (one of the downtown districts of Chengdu): Chengdu and Hua Neng, which were located in close proximity to one another. ${ }^{15}$ The first public announcement of the eventual plants' closures was on January 24, 2006. ${ }^{16}$ At that point, neither the date nor the order of the closures (i.e. whether the two plants will be closed together or one after another) was announced.

Chengdu power plant was eventually closed on July 16, 2006. This plant, constructed in 1951 and formally put into production in 1955, was the first large thermal power plant that

\footnotetext{
${ }^{10}$ Chengdu is one of the top-5 cities in China after Beijing, Shanghai, Guangzhou and Shenzhen.

11 Particles less than $10 \mu \mathrm{m}$ in diameter (PM10) pose health concerns because they can be inhaled into and accumulate in the respiratory system; particles less than $2.5 \mu \mathrm{m}$ in diameter (PM2.5), referred to as finer particles, pose greatest health risks because they can lodge deeply into the lungs due to their small size.

12 https://english.mep.gov.cn.

13 Environmental control measures have continued in Chengdu. The subsequent Twelfth Five-Year Plan (2011-2015) had, among other objectives, to further reduce pollutant emission in the city by continuing to shut down outdated industrial production facilities and promoting the use of environmentally-friendly manufacturing processes, supporting the use of clean and renewable fuels, and putting forward stricter demands to reduce the emission of nitrogen, sulfur and other toxic elements.

14 For further details see Chengdu Municipal Government (2006).

15 The third plant that remained operating in the area, Jia Ling, was closed later (August 2011). This plant was built in 1997 and started operations in 1999 but was less polluting than the other two plants.

${ }^{16}$ China Environmental News, https://www.envir.gov.cn/info/2006/1/124595.htm.
} 
could both generate electricity and heat in Southwest China. However, due to their aged machinery and equipment and a sewage system that failed to meet the new environmental standards, it imposed an enormous amount of pressure on the environmental protection of the eastern side of the city. According to the Chengdu Municipal Environmental Protection Bureau, this plant discharged about 4.2 thousand tons of soot and dust each year and its emissions of sulfur dioxide were up to 7.8 thousand tons per year. ${ }^{17}$

Approximately a year after Chengdu power plant was closed, Hua Neng plant was shut down on June 16, 2007. Hua Neng power plant, built in 1988, was a fast-track project to help resolve the electricity shortage in Chengdu at that time, and went into operation in 1990. Despite adopting electrostatic precipitator technologies to prevent excessive discharge of soot, the plant was discharging large amounts of dust due to the lack of desulfurization equipment, aged machinery and equipment failure. Hua Neng power plant caused more harm to the environment than Chengdu power plant. The plant emitted about 8 thousand tons of soot and dust and discharged 19 thousand tons of sulfur dioxide into the air every year.

In sum, Chengdu and Hua Neng power plants were a major source of pollution emitting a significant amount of pollutants and toxic residues. The two plants contributed with close to $6 \%$ of total inhalable particles in the city and with over $27 \%$ of total sulfur dioxide in the air. These issues were certainly larger than the benefits of having the plants nearby in terms of, for example, lower electricity transmission and delivery costs. ${ }^{18}$ Once the plants were closed and demolished, new apartment buildings were built on the same plants' site as well as on the surroundings. ${ }^{19}$ We exploit the closing of these two major power plants to evaluate the effect of changes in the quality of the environment on the housing market. We compare variations in both prices and the volume of housing transactions within five kilometers of the plants relative to neighboring areas in the city center.

Units located closer to the plants are expected to be more affected than those located farther away in terms of pollutants, toxic residues, noise and visual disamenities. Establishing, however, the exact extent of the affected areas is more an empirical matter since the level of concentration and atmospheric dispersion of fine particular matter from the source of pollution (i.e. the plants) depends on meteorological conditions, geography and the type of infrastructure in the area, among other factors (see eg., Levy et al. 2000, 2002; Ames et al. 2002; Schlenker and Walker 2016). Davis (2011), for example, evaluates the effect of US fossil fuel plants on house values within a radius of two miles relative to house values farther away. ${ }^{20}$ His analysis is though based on plants that began operations between 1993 and 2000, i.e. plants that are cleaner and have more advanced production and dust removal technologies than Chengdu and Hua Neng power plants, while the environmental regulations were further less stringent in China during the period of analysis.

\footnotetext{
17 https://www.cdepb.gov.cn/index.asp.

18 Electricity prices did not increase after the relocation since besides building a more efficient power plant in Jintang County, the Chengdu Government started to rely more on hydroelectric power (instead of thermal power) as Sichuan Province is abundant in hydraulic resources.

19 The apartment complex where Chengdu plant was specifically located is called Shang Lin Dong Fang while the apartment complex where Hua Neng plant was located is called Dong Fang Tian Di. The new units built in these complexes were sold after the relocation of the two plants and the results are not sensitive to excluding them from the analysis.

20 The author also finds somewhat larger effects within a radius of one mile and does not find significant effects beyond four miles.
} 
In this line, we consider a treatment radius of five kilometers but evaluate the robustness of our results to alternative distance thresholds. Similarly, we examine whether housing units located downwind of the power plants experience a higher increase in prices. We further assess the sensitivity of our results to potential anticipated behavior as the public announcements of the plants' closures occurred a couple of months prior to the effective closings.

Figure 1 shows the air quality within and beyond five kilometers of the plants for the period 2002-2011. ${ }^{21} \mathrm{We}$ observe that the air pollution index in the area closer to the plants steadily decreased from 96 in 2005 to 92 in 2006, 85 in 2007 and 81 in 2008, likely driven by the closing of Chengdu and Hua Neng power plants considering that no other major polluting source operating in the area was shut down in 2006-2007 (neither we are aware of a specific policy change). In the rest of the city, the air quality also improved, but to a lesser extent (from 85-89 to 80-81). The figure further shows that after the closing of the plants the air quality in the proximity of the plants remained, on average, very similar to the rest of the downtown area.

The shutdown of the two power plants also likely reduced other local negative externalities in the area driving prices and volume of transactions upward. Power plants are a source of additional negative externalities that are relatively important for households living close to the plants such as noise and visual disamenities, which can be particularly acute for large power plants like Chengdu and Hua Neng plants. ${ }^{22}$ There are also neighborhood externalities in the sense that the association of an area with environmental contamination can affect the neighborhood quality in terms of the composition of residents and other local attributes. $^{23}$ The different attributes and amenities available in the new apartment complexes built in the areas closer to the plants could also have relatively increased after the relocations thereby further increasing prices, and we explore this potential effect on prices in the empirical results.

It is worth indicating that the plants' relocations did not result in massive layoffs neither led workers and their families to move away from the city. The new power plant was built in Jintang County, one of the suburb counties of Chengdu located $49 \mathrm{~km}$ east of the city center and workers were provided temporal housing next to the new plant for their work shifts, while their families remained in the city. Reports from the Chengdu Bureau of Statistics and Chengdu Hi-Tech Industrial Development Zone also show that the economic activity, number of enterprises and level of employment continued to increase in Chenghua district (where the plants were located), as well as in the other downtown districts. ${ }^{24}$

\footnotetext{
21 Since the pollution data for the period of the study is only available at the district level, the values reported are a weighted average of the district values using as weights the number of housing units in each corresponding downtown district in our census data located within and more than five kilometers of the plants. We do the same when discussing other district-level variables below. We acknowledge that the pollution indicators, which are based on official data, could be subject to underreporting. Yet, data manipulation (if any) is most likely to occur around the cutoff level of 100 on particular days and not throughout the whole year (Ghanem and Zhang, 2014).

22 Certainly, noise and traffic could also increase with the development of the area surrounding the plants, but these potential negative externalities are significantly smaller than the ones generated by the plants.

${ }^{23}$ See, for example, McCluskey and Rausser (2003) who evaluate the existence of environmental and neighborhood externalities in the residential housing market near a hazardous waste site in Dallas, Texas.

${ }^{24}$ Chengdu Bureau of Statistics: https://cdstats.chengdu.gov.cn; Chengdu Hi-Tech Industrial Development Zone: https://www.cdht.gov.cn (In Chinese).
} 


\section{Empirical Approach}

\subsection{Data}

The data used in the analysis are obtained from the Housing Authority transaction system of Chengdu and includes all daily real estate transactions for new housing units purchased in the downtown area between January 2005 and May 2009. ${ }^{25}$ The data exclude secondhand unit sales, but this market was very small during the period of the study compared to the market for new units. ${ }^{26}$ The dataset includes information on the house purchase date, transaction price, location, building developer, unit area and floor (in the case of apartments), building type and building status. The address information also permits to geocode the location of the units and calculate their distance to the power plants. Figure 2 maps the treatment area and all six downtown districts covered by the dataset, including Chenghua district where the plants were located as well as the neighboring districts of Gaoxin, Jinjiang, Jinniu, Qingyang and Wuhou.

We restrict our sample to new apartments in residential buildings, which represent more than $97 \%$ of the total housing transactions observed in our full sample. This allows us to base the analysis on comparable apartment units located in the downtown area, considering that the type of homebuyers looking for a new house may differ both by location (downtown vs. suburbs) and type of building. ${ }^{27}$ In the same vein, we further limit our sample to forward contract transactions (i.e. sales where the buyer does not necessarily immediately moves in because the building might still be under construction), as the vast majority of new house purchases in China are made through forward contracts (96\% in our sample). ${ }^{28}$ Lastly, we exclude from the analysis all housing purchases that occurred during the months of the power plants' closures (July 2006 and June 2007) to avoid any potential noise during the months of the relocations and better distinguish between the periods before and after the closures. ${ }^{29}$ Hence, we divide our full sample into three subsamples: (1) baseline period from January 2005 to June 2006 (Period 0); (2) first follow-up period after relocation of Chengdu power plant, from August 2006 to May 2007 (Period 1); and (3) second follow-up period after relocation of Hua Neng power plant, from July 2007 to May 2009 (Period 2). We use a total of 361,936 observations for the analysis.

We supplement this housing transaction data with demographic and socioeconomic characteristics at the district level. These data are obtained from the Chengdu Bureau of Statistics and the Chengdu Hi-Tech Industrial Development Zone statistical yearbooks. The

\footnotetext{
25 Similar to the rest of China, all sales must be registered in the Housing Authority transaction system.

26 According to aggregate data obtained from the Chengdu Housing Authority, between 2005 and 2009 the sales of new housing units represented a total of 48.2 million square meters versus 1.7 million square meters for second-hand units (487,808 versus 20,255 in terms of housing units sold). In addition, the area occupied by second-hand units was $25.7 \%$ of the total housing area.

27 Most of the housing supply in urban areas in China are apartment buildings. Still, the type of consumers looking for a village might be different that those looking for an apartment unit.

28 The Urban Real Estate Administration Law of China requires that the amount invested in the building construction must be at least $25 \%$ of the total construction investment for a forward sale to occur. The results though are similar when considering non-forward transactions.

29 The estimation results are not sensitive to excluding, instead, the period of two weeks or two months around the closing of the plants. It is also worth noting that it generally takes around 5 working days for a transaction to be completed and recorded, based on conversations with local real estate agents, bank credit specialists and staff from the Housing Authority of Chengdu.
} 
110.0

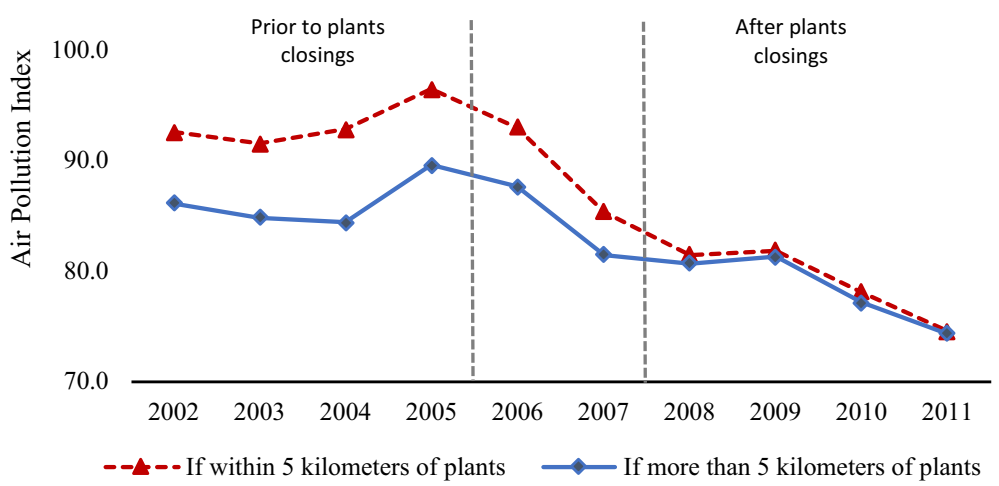

Fig. 1 Average annual air pollution level in downtown areas surrounding power plants, 2002-2011. Note: The air pollution index (or air quality index) is based on five atmospheric pollutants, including fine particular matter of less than $10 \mu \mathrm{m}$ in diameter (PM10), sulfur dioxide $\left(\mathrm{SO}_{2}\right)$, nitrogen dioxide $\left(\mathrm{NO}_{2}\right)$, carbon monoxide $(\mathrm{CO})$ and ozone $\left(\mathrm{O}_{3}\right)$. Data obtained at the district level from the Ministry of Enviroment Protection of China and Chengdu Municipal Environmental Protection Bureau. The annual values reported are a weighted average of the district values using as weights the number of housing units in each corresponding district in our census data located within and more than five kilometers of the plants. The downtown districts include Chenghua (where plants were located), Gaoxin, Jinjiang, Jinniu, Quinyang and Wuhou

district variables include population density, per capita income and household size, which are available for all years of the study. ${ }^{30}$

Table 1 presents descriptive statistics of the variables used in the study. In the top panel, we report summary statistics at the unit level for the full sample and the three subsample periods considered for the regression analysis. The average price per square meter of a new apartment bought in downtown Chengdu during the sample period is about $4901 \mathrm{RMB}$ (644 US dollars), while the average unit size is 99 square meters. We observe that prices in the downtown area consistently increased across time, by 712 RMB (18.5\%) from January 2005-June 2006 to August 2006-May 2007, and by an additional 948 RMB (20.8\%) from August 2006-May 2007 to July 2007-May 2009. This upward trend is in line with the evolution of the national housing price index between 2005 and 2009, reported by the National Bureau of Statistics of China. We also observe an increase in upper-floor units and a larger fraction of units built by a top Chinese developer (proxy of quality). ${ }^{31}$ Overall, $24 \%$ of the

\footnotetext{
${ }^{30}$ Neighborhood characteristics like number of schools or hospital beds are available but only for a specific year, reason why we do not include them in the analysis. In terms of transportation facilities (i.e. bus, metro), all the downtown area is generally well connected. As far as we are aware of, there were also no major changes neither differential changes across locations in public services during the period of the study.

31 Units in upper floors are generally charged a floor-premium due to their additional attributes in terms of better view, lesser noise and fresher air than lower-floor units (Benson et al. 1998; Chau et al. 2004; Glaeser et al. 2005). A top or major developer is a construction company listed among the Top 100 China Real Estate Developers published every year since 2005 by the Development Research Center of the China State Council, Real Estate Research Institute of Tsinghua University and China Index Research Institute; the companies are ranked based on their investment scale and growth, business performance and profitability.
} 


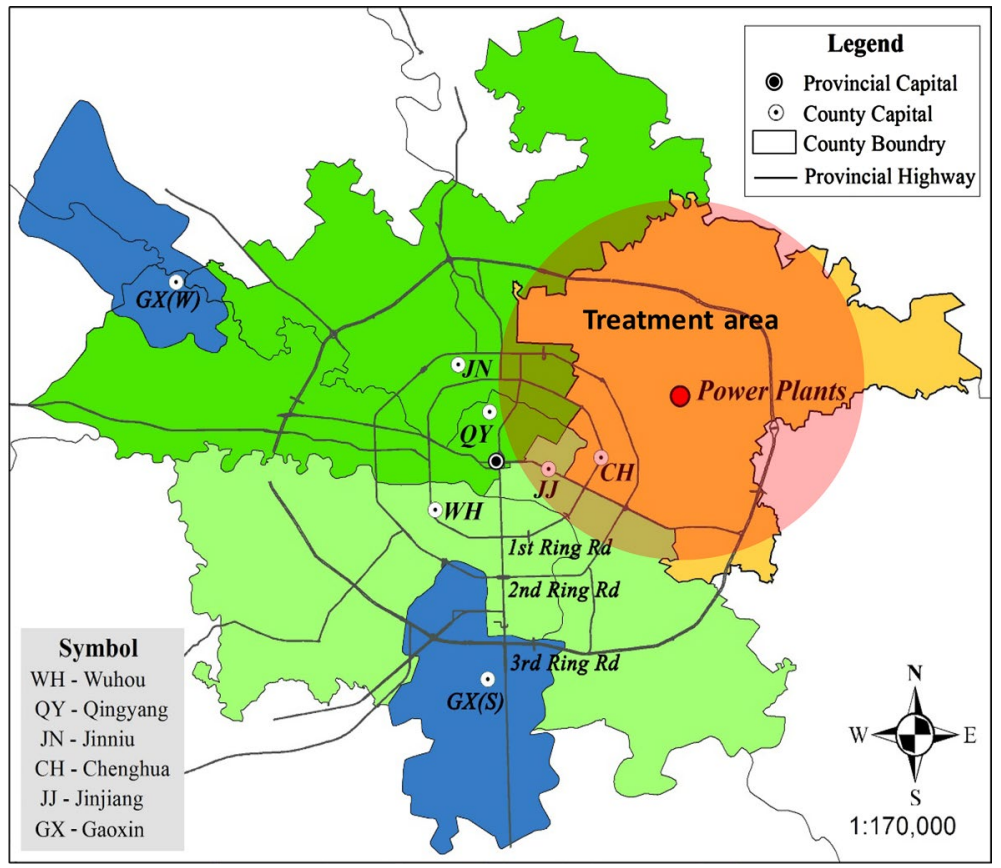

Fig. 2 Map of downtown area included in the study and location of power plants. Note: The treatment area comprises an area of five kilometers around the location of the power plants. Gaoxin is a non-administrative district which includes both a West area, GX(W), and a South area, GX(S)

units in the sample are located within five kilometers of the plants' location, most of them in Chenghua district. ${ }^{32}$

The bottom panel of the figure also shows an important rise in the volume of new home purchases in the downtown area during the period of study. The average number of weekly transactions in the area monotonically increased from 79 purchases (per ring of one kilometer radius) in January 2005-June 2006 to 113 purchases in August 2006-May 2007 and 131 purchases in July 2007-May 2009. This general increase in transactions (and prices) is in line with the fact that the Chengdu housing market for new houses has been one of the most dynamic in China over the past two decades. ${ }^{33}$

\subsubsection{Preliminary Analysis}

As a preliminary assessment, Figure A.1 in Appendix A reports average prices (Panel A) and volume of transactions (Panel B) within and more than five kilometers of the two plants' location, before and after the plants' closings. The figure also plots the corresponding ratio of average prices and transactions between the two areas. We observe a higher increase in housing prices in the areas located closer to the plants after the relocations. The

\footnotetext{
32 In particular, $73 \%$ are located in Chenghua, $23 \%$ in Jinjiang and the remaining $4 \%$ in the other districts.

33 In fact, we observe transactions in 3246 out of 3270 possible ring-weeks in our sample period; that is, there are only $0.73 \%$ cases where we do not observe any home purchase in a particular week and ring, reason why we work at the week level for transactions.
} 
Table 1 Summary statistics

\begin{tabular}{|c|c|c|c|c|c|c|c|c|}
\hline \multirow[t]{2}{*}{ Variable } & \multicolumn{2}{|c|}{$\begin{array}{l}\text { Jan 2005-Jun } \\
2006\end{array}$} & \multicolumn{2}{|c|}{$\begin{array}{l}\text { Aug 2006-May } \\
2007\end{array}$} & \multicolumn{2}{|c|}{$\begin{array}{l}\text { Jul 2007-May } \\
2009\end{array}$} & \multicolumn{2}{|c|}{ Full sample } \\
\hline & Mean & $\mathrm{SD}$ & Mean & SD & Mean & SD & Mean & SD \\
\hline \multicolumn{9}{|l|}{ Panel A: At the unit level } \\
\hline Price (Yuan per square meter) & 3849 & 995 & 4561 & 1041 & 5508 & 1528 & 4901 & 1499 \\
\hline Unit size (square meters) & 103.92 & 45.79 & 106.57 & 36.20 & 94.45 & 31.00 & 99.28 & 36.67 \\
\hline Floor level & 8.09 & 5.79 & 10.44 & 6.72 & 13.06 & 8.08 & 11.29 & 7.59 \\
\hline If top developer & 0.19 & 0.39 & 0.23 & 0.42 & 0.33 & 0.47 & 0.27 & 0.45 \\
\hline If elevator in building & 0.83 & 0.37 & 0.97 & 0.18 & 0.99 & 0.08 & 0.95 & 0.22 \\
\hline If within $5 \mathrm{~km}$ of plants & 0.21 & 0.41 & 0.22 & 0.41 & 0.26 & 0.44 & 0.24 & 0.43 \\
\hline Located in circle center & 0.11 & 0.31 & 0.05 & 0.22 & 0.05 & 0.21 & 0.06 & 0.24 \\
\hline $\begin{array}{l}\text { Located between circle center- } \\
\text { circle } 1\end{array}$ & 0.04 & 0.19 & 0.02 & 0.15 & 0.02 & 0.16 & 0.03 & 0.16 \\
\hline Located between circle 1 -circle 2 & 0.15 & 0.36 & 0.11 & 0.31 & 0.12 & 0.32 & 0.13 & 0.33 \\
\hline Located between circle 2 -circle 3 & 0.51 & 0.50 & 0.63 & 0.48 & 0.53 & 0.50 & 0.55 & 0.50 \\
\hline Located outside circle 3 & 0.19 & 0.39 & 0.19 & 0.39 & 0.28 & 0.45 & 0.24 & 0.42 \\
\hline $\begin{array}{l}\text { Population density (population per } \\
\text { square } \mathrm{km} \text { ) }\end{array}$ & 5794 & 1574 & 5955 & 1426 & 6036 & 1455 & 5959 & 1483 \\
\hline Per capita annual income (Yuan) & 50,751 & 14,419 & 54,465 & 16,019 & 66,113 & 21,083 & 59,905 & 19,879 \\
\hline Household size & 2.93 & 0.06 & 2.91 & 0.10 & 2.85 & 0.12 & 2.88 & 0.11 \\
\hline \#Observations & & 90,391 & & 73,698 & & 197,847 & & 361,936 \\
\hline \multicolumn{9}{|c|}{ Panel B: At the ring level (of one kilometer radius) } \\
\hline Weekly volume of transactions & 79 & 75 & 113 & 107 & 131 & 121 & 110 & 107 \\
\hline \#Observations & & 1122 & & 630 & & 1494 & & 3246 \\
\hline
\end{tabular}

In Panel B, the rings correspond to separate rings of one kilometer radius around the location of the power plants

SD Standard deviation

average price per square meter within five kilometers of the plants increased from 3714 RMB prior to the relocation to $5773 \mathrm{RMB}$ after the closing of the two plants, equivalent to a 55.4\% increase; prices in the other downtown areas increased from 3885 to 5415 RMB (39.4\% increase). The housing market in the vicinity of the plants also exhibited a much higher dynamism in terms of volume of transactions, particularly after the relocation of both plants. Average weekly purchases of apartment units increased by $108.9 \%$ within five kilometers (from 61 to 128 transactions per radius of one kilometer) versus $58.3 \%$ in areas farther away (from 83 to 132 transactions).

Figure 3 offers more detailed insights about the evolution of prices (Panel A) and volume of transactions (Panel B) in the affected and surrounding areas. The figure plots the monthly evolution of prices and weekly volume of transactions across areas within and beyond five kilometers around the plants (and their corresponding differences) over the study period. Several interesting patterns emerge from the figure. First, prices and weekly transactions seem to move in a similar fashion across both areas. Second, the price differentials (reported in bars) between apartment units located within and more than five kilometers of the plants generally decrease (or reverse in some months) after the closing of the first plant in July 2006 and reverse after the closing of the second plant in June 2007; prior 
to the plants' relocations, housing prices per square meter were up to $600 \mathrm{RMB}$ lower in areas within five kilometers of the plants than farther away; after the relocations, prices were up to $900 \mathrm{RMB}$ larger within five kilometers of the plants. Third, the differences in the volume of transactions decrease and eventually disappear after the relocation of the second plant with over 100 weekly transactions (per radius of one kilometer) in both areas during the period July 2007-May 2009.

The apparent co-movement in prices and volume of transactions across areas provides some support for the implementation of a DID and CIC approach to evaluate the potential effect of the power plants' relocation on housing prices and transactions. An assumption that validates the use of these methods is that the underlying trend in the outcome variable is similar in the treatment group (areas within five kilometers of plants) and the comparison group (areas more than five kilometers of plants) used to construct a counterfactual state for the former group. While this assumption is never testable, Fig. 3 sheds some light on its plausibility.

We further implemented a standard event-study analysis for daily prices reported in Figure A.2 in Appendix A. We observe that prior to the plants' relocations the monthly changes in housing prices within five kilometers of the plants were generally not statistically different than the changes in prices more than five kilometers away of the plants, as opposed to the period after the relocations. ${ }^{34}$ This pattern of relative changes in housing prices provides additional support for our research design. Although not reported, placebo tests assuming that the relocations started prior to July 2006 also support our empirical approach. $^{35}$

Table A.1 in Appendix A reports, in turn, average socioeconomic and housing characteristics of the treatment and control areas for the years 2005-2009. While we observe some differences across areas, which we account for in the regression analysis, it is interesting that most of the socioeconomic and housing characteristics changed in a similar direction across these areas. We find, for example, an increase in the per capita annual income of the households living in downtown areas both near and farther away from the plants, in real estate investment, population density and the buildings height (number of floors), as well as a decrease in household size and unit size. These similar variations in observable characteristics across areas also support the use of a DID and CIC approach, although we cannot completely discard time-varying differences in other (unobserved) location-specific variables. ${ }^{36}$

\footnotetext{
${ }^{34}$ We regressed the log of price per square meter of an apartment unit on monthly indicators (using January 2005 as the base category), the interaction of these monthly indicators with a dummy variable equal to one if the unit is located within five kilometers of the plants, and the set of housing and district controls used for the main estimations. We report the coefficients of the interaction terms between the monthly indicators and the dummy variable for within five kilometers of the plants, which capture the corresponding differential change in monthly prices between units located within five kilometers of the plants and units locater farther away.

${ }^{35}$ We alternatively assumed that the relocations started on June 2005, September 2005, December 2005 or March 2006 and we do not find statistically significant treatment effects at conventional levels. Further details are available upon request.

${ }^{36}$ Among the variations in observable characteristics, the only important difference between areas is the proportion of apartment units built by a top (major) developer. The relocation of the power plants seems to have considerably increased the presence of top developers in their vicinity compared to areas farther away. Since top developers may also proxy for unit quality, this could also have attracted a higher proportion of buyers looking for structures of higher quality in the vicinity (besides a better environment). However, the results are not sensitive to separately performing estimations for units built by top and non-top developers.
} 
Panel A: Prices

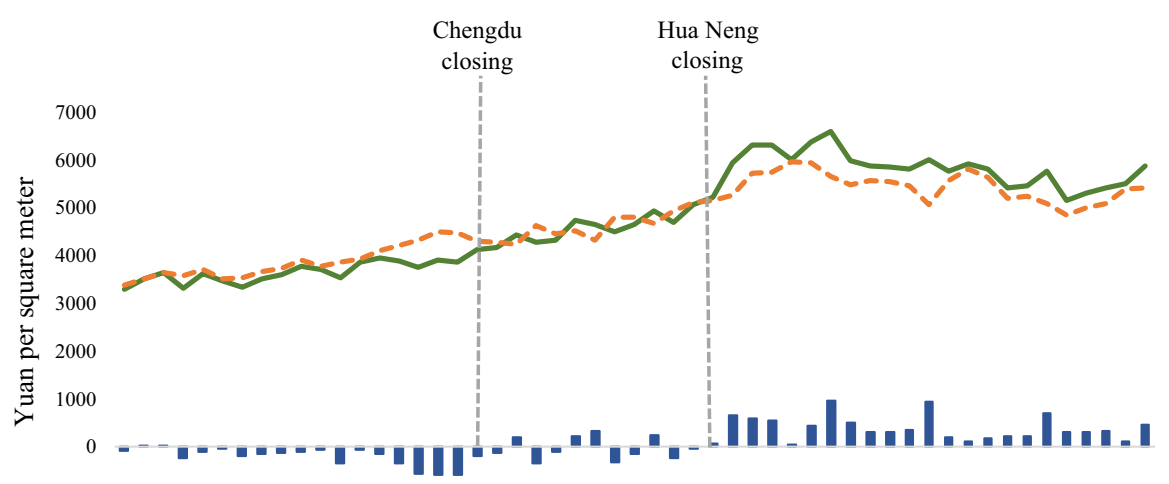

$-10002005 \mathrm{~m} 12005 \mathrm{~m} 52005 \mathrm{~m} 92006 \mathrm{~m} 12006 \mathrm{~m} 5$ 2006m9 2007m1 2007m5 2007m9 2008m1 2008m5 2008m9 2009m1 2009m5

Price difference If within 5 kilometers of plants $\quad$ - $\quad-$ More than 5 kilometers of plants

Panel B: Weekly volume of transactions

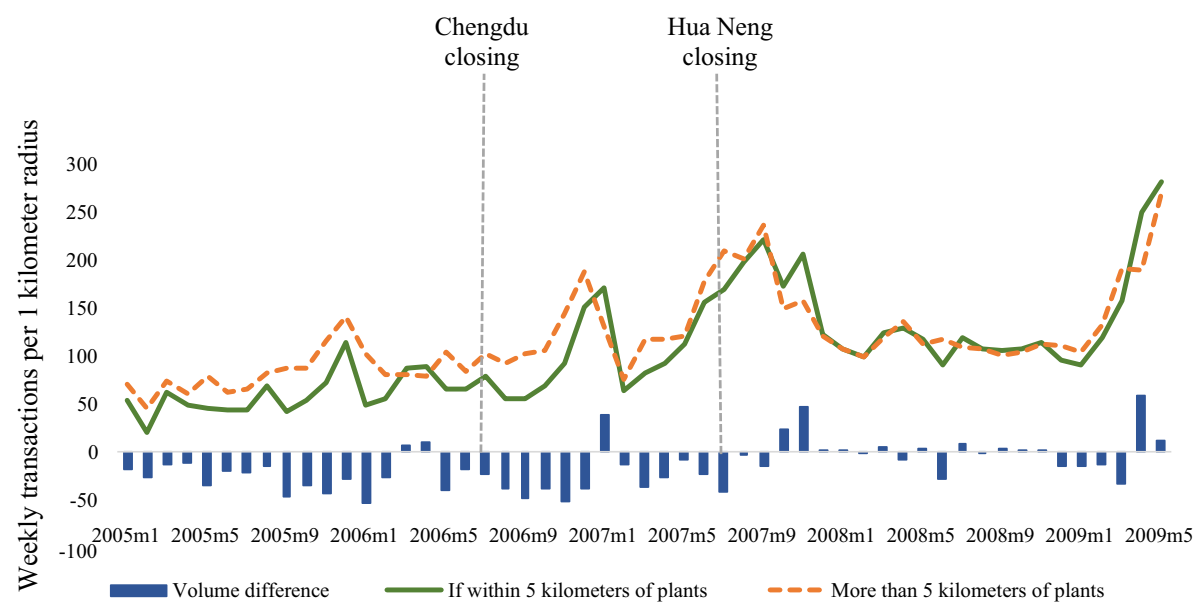

Fig. 3 Monthly evolution of housing prices and volume of transactions in downtown areas sorrounding power plants. Note: The downtown districts include Chenghua (where plants were located), Gaoxin, Jinjiang, Jinniu, Quinyang and Wuhou. The price (volume) difference is the monthly difference between average prices (weekly transactions) within five kilometers of the plants and more than five kilometers of the plants

\subsection{Methodology}

This section describes the empirical model used to examine the effect of the relocation of Chengdu and Hua Neng power plants on housing prices and volume of transactions. The closing of the two plants provides a quasi-natural setting to compare variations in market outcomes likely driven by an improvement in environmental quality in neighborhoods near the plants relative to neighborhoods farther away. Our extensive dataset permits us to focus on the purchase of similar new housing units across different comparable downtown areas, over a reasonable period of time before and after the plants' relocation. We follow a DID approach to evaluate average effects on prices and volume 
of transactions, as well as a CIC method to analyze varying effects across the price distribution.

We estimate the following log-linear price model,

$$
\ln p_{i j t}=\alpha+\beta T+\delta_{s} t_{s}+\gamma_{s} T * t_{s}+X_{i j t} \lambda+N_{j t} \theta+\varepsilon_{i j t}
$$

where $p_{i j t}$ is the price per square meter of apartment unit $i$ located in district $j$ and purchased at day $t ; T$ is a dummy variable equal to one if the unit is located within five kilometers of the plants; $t_{s}, s=1,2$, are dummy variables equal to one for purchases made during August 2006-May $2007(s=1)$ and July 2007-May $2009(s=2) ; X_{i j t}$ is a vector of housing controls; $N_{j t}$ is a vector of district controls; and $\varepsilon_{i j t}$ is an error term. The housing controls include apartment size, floor level where the unit is located, a dummy variable indicating whether the building is constructed by a top developer (proxy of quality) and if the building has elevator. ${ }^{37}$ The district controls include population density, per capita income and household size. We also account for location and time effects to control for possible unobserved time-invariant differences across locations as well as common shocks and seasonal patterns in Chengdu's downtown housing market. We control for the location of the unit relative to the city center (using the inner-city traffic circles as a reference) and include year-quarter fixed effects. ${ }^{38}$

The parameters of interest in Eq. (1) are $\gamma_{1}$ and $\gamma_{2}$, which compare average changes in house prices within five kilometers of the plants relative to neighboring areas located farther away, before and after the relocation of Chengdu power plant $\left(\gamma_{1}\right)$ and before and after the relocation of both Chengdu and Hua Neng power plants $\left(\gamma_{2}\right)$. These DID estimators approximate an average treatment effect on the treated (ATT) under two assumptions (Ashenfelter and Card 1985; Abadie 2005). ${ }^{39}$ In this case the treatment or intervention is the closure of the plants and the treatment group are the apartment units located within a radius of five kilometers of the plants $(T=1)$. Hence, $\gamma_{1}$ and $\gamma_{2}$ capture $\mathrm{ATT}_{\mathrm{s}} \equiv E\left[P^{C}-P^{N C} \mid T=1, t_{s}=1\right], s=1,2$, where $P^{C}$ is the price of an apartment unit within five kilometers of the plants after the plant(s) closure, and is $P^{N C}$ is the price of the unit had the plants not been closed.

This model permits us to test whether the relocation of the power plants results in an increase in housing prices. In line with a standard hedonic price model, we expect a rise in housing prices after the closing of the power plants driven by an improvement in environmental quality in the affected areas. Considering that environmental quality is a normal good, an improvement in environmental quality will lead to a higher housing price

\footnotetext{
37 We do not have information on other unit characteristics like number of bedrooms/bathrooms or balconies, although apartment unit plans in urban areas in China are generally more homogenous than in other countries (Kong et al. 2008). The inclusion of the building height where the unit is located does not materially affect our estimation results. We exclude this variable from the analysis because we only have this information for less than half of the transactions in our sample.

38 Chengdu has 1-h, 2-h, and 3-h inner-city traffic circles around the city center. The results are also robust to using district fixed effects or to the inclusion of district-specific time trends instead of year-quarter fixed effects.

39 The first assumption involves a common trend assumption, which assumes that if all observations had remained untreated, the average outcome would have followed parallel trends before and after the intervention between the treatment and comparison group. The second assumption is the full compliance assumption, which assumes a full treatment rate among the treatment group and a zero treatment rate among the control group and prior to the intervention.
} 
as typically characterized in a hedonic equilibrium (see eg., Rosen 1974; Freeman 2003; Bajari and Benkard 2005; Davis 2011).

Similarly, we estimate a log-linear volume of transactions model given by,

$$
\ln q_{r w}=\alpha+\beta T+\delta_{s} t_{s}+\gamma_{s} T * t_{s}+X_{r w} \lambda+N_{r w} \theta+\varepsilon_{r w}
$$

where $q_{r w}$ is the number of apartment units' transactions per week $w$ for each ring $r$ of 0-1 km, 1-2 km, 2-3 km, and so forth, around the plants. The control variables are similar to the ones used in the price model in Eq. (1), except that we replace the housing and district characteristics with the corresponding median values for each week-ring $\left(X_{r w}\right.$ and $\left.N_{r w}\right)^{40}$

Parameters $\gamma_{1}$ and $\gamma_{2}$ measure the average effect of the plants' relocation on the volume of housing transactions in the treatment group. They capture average changes in the volume of weekly housing transactions within versus more than five kilometers around the plants, before and after the relocation of Chengdu plant and before and after the relocation of both Chengdu and Hua Neng plants.

This second model allows us to evaluate the effect of power plants' relocations on the volume of housing transactions. As opposed to prices, an increase in the volume of transactions is not necessarily a direct prediction in hedonic equilibrium. Following Davis (2011), it is reasonable to assume that a local increase in environmental quality will result in a parallel shift in housing demand (while the hedonic price schedule remains constant). Yet, if housing availability is large enough and continuously expanding in the affected area, which seemed to be the case in our data of new apartment units, we may also observe an increase in the volume of sales in the surrounding areas even in the short run. According to market reports by E-House China Research Institution, several major real estate projects started in the area following the plants' relocation. ${ }^{41}$

Finally, we implement the CIC approach proposed by Athey and Imbens (2006) to examine variations in the entire distribution of housing prices in the affected versus adjacent areas, before and after the relocation of the power plants. This method permits us to uncover varying effects of the plants' closure across different price percentiles. Compared to the DID model where we approximate average counterfactual outcomes in the absence of the treatment or intervention, in the CIC model we estimate the whole counterfactual distribution of outcomes. The CIC model is also more general than the DID model in that it allows the distribution of unobservables to vary across the treatment and control groups in arbitrary ways. For example, groups may differ in terms of the distribution of outcomes in the absence of the intervention as well as on the effects of the intervention.

In the CIC model, we estimate a distributional treatment effect on the treated or DTT equivalent to $\Delta_{s}(q) \equiv F_{P^{C} \mid T=1, t_{s}=1}^{-1}(q)-F_{P^{N C} \mid T=1, t_{\mathrm{s}}=1}^{-1}(q), s=1,2$, where $q \in[0,1]$ is a specific percentile and $F$ is the cumulative distribution function of housing prices. While $F\left(P^{C} \mid T=1, t_{s}=1\right)$ is directly obtained using observed data in the treatment area, $F\left(P^{N C} \mid T=1, t_{s}=1\right)$ is not directly observed and must be estimated. Athey and Imbens (2006) indicate that under certain assumptions, the counterfactual distribution of prices can be described as,

\footnotetext{
40 The results are robust to using ring fixed effects or using mean control values (instead of median values). We also find similar results when alternatively aggregating and estimating the model at the monthly level, although the number of observations is considerably lower.

41 Note that a supply expansion, following a demand outward shift, would also attenuate the observed increase in equilibrium prices, as discussed later.
} 


$$
F\left(P^{N C} \mid T=1, t_{s}=1\right) \equiv F_{P^{N C}, 11}(p)=F_{P^{N C}, 10}\left[F_{P^{N C}, 00}^{-1}\left(F_{P^{N C}, 01}(p)\right)\right] .
$$

We present the proof of expression (3) in Appendix B assuming a linear price model similar to the one used in this study. ${ }^{42}$ By inverse transformation, we can then calculate the effect of the intervention (i.e. the plants' relocation) for a given percentile $q$,

$$
\tau_{s, q}^{C I C} \equiv F_{P^{C}, 11}^{-1}(q)-F_{P^{N C}, 11}^{-1}(q)=F_{P^{C}, 11}^{-1}(q)-F_{P^{N C}, 01}^{-1}\left[F_{P^{N C}, 00}\left(F_{P^{N C}, 10}^{-1}(q)\right)\right] .
$$

We estimate $F$ (and its inverse) using the standard plug-in method to derive empirical cumulative distribution functions. Athey and Imbens (2006) show that estimator $\tau_{s, q}^{C I C}$ has an asymptotically normal distribution and recommend using bootstrapping to calculate its variance.

The CIC approach also permits to account for covariates in the analysis. In particular, we first regress a log-linear price model similar to one specified in Eq. (1) and recover $\ln \tilde{p}_{i j t}=\ln p_{i j t}-X_{i j t} \hat{\lambda}-N_{j t} \hat{\theta}$. We then implement the CIC method on $\ln \tilde{p}_{i j t}$. We evaluate distributional effects after the relocation of Chengdu plant (August 2006-May 2007 vs. January 2005-June 2006), and after the relocation of both Chengdu and Hua Neng power plants (July 2007-May 2009 vs. January 2005-June 2006).

This third model permits us to examine if more expensive houses show a higher increase in prices after the closure of the plants. Following the hedonic price framework, more expensive houses should exhibit a higher increase in prices driven by an improvement in environmental quality after the power plants' relocation. The underlying intuition is that higher income consumers are willing to pay more for housing than lower income consumers when faced with a similar degree of environmental improvement. As more expensive houses are usually purchased by high income consumers, we should expect an increasing change in housing prices as we move along the price distribution after the plants' relocation. ${ }^{43}$

Another way to rationalize the expected increasing change in housing prices is by taking into account that environmental quality is complementary to other housing features that consumers generally value. Since expensive houses are associated with better housing attributes (besides environmental quality), an increase in environmental quality leads to a higher general increase in the housing quality of expensive houses. As a result, higher priced houses should exhibit a larger increase in prices after the closure of the plants.

\section{Results}

In this section, we first discuss the regression results of the DID and CIC models. We then perform additional estimations and robustness checks to further assess the validity of our results. Lastly, we quantify the aggregate effect of the plants' closure on the local housing market for new units.

\footnotetext{
42 The conditions to identify the counterfactual distribution of prices include: (i) prices satisfy the following relationship in the absence of intervention $P^{N C}=h\left(E, t_{s}\right)$, where $E$ represents the set of unobservables $\varepsilon$; (ii) $P^{N C}$ is a monotone increasing function of $\varepsilon$; (iii) any differences between groups remain stable across time, i.e. $E \perp t_{s} \mid T$; and (iv) $\Gamma_{1} \subseteq \Gamma_{0}$ where $\Gamma_{1}$ and $\Gamma_{0}$ are the corresponding domains of $F(\varepsilon \mid T=1)$ and $F(\varepsilon \mid T=0)$.

43 Formally showing this finding in a general hedonic price model, as in Bajari and Benkard (2005), requires though imposing additional assumptions. In particular, we need to introduce a consumer preference parameter and assume a relationship with income as in Epple and Platt (1998).
} 


\subsection{Base Results}

Table 2 reports the estimation results of the DID price model defined in Eq. (1). This model allows us to examine whether the relocation of the power plants increased average housing prices in the vicinity of the plants relative to comparable areas farther away (i.e. measure the average treatment effect). In column (1) we estimate the model using the full sample, while in columns (2) and (3) we separately compare between the period after the relocation of Chengdu power plant and the base period (Period 1 vs. Period 0), and between the period after the relocation of both Chengdu and Hua Neng power plants and the base period (Period 2 vs. Period 0). District controls and year-quarter fixed effects are omitted in the table (and throughout the rest of the paper) for ease of presentation. The reported standard errors are robust and clustered by district and month. ${ }^{44}$

The estimations show a general increase in housing prices in the downtown area of Chengdu after the closing of the power plants. However, in line with our preliminary graphical analysis, we observe a higher increase in prices within five kilometers of the plants compared to neighborhoods farther away. Based on the full sample results (first column), the price per square meter within five kilometers of both plants increased by an additional $12.1 \%$ after the relocation of Chengdu power plant (period August 2006-May 2007) and by $14.3 \%$ after the relocation of both Chengdu and Hua Neng power plants (period July 2007-May 2009) relative to the base period (January 2005-June 2006). ${ }^{45}$ When separately comparing across periods, the corresponding increase is $13 \%$ in the first case and $14 \%$ in the second case. While the context in the US is different, the estimated price change is between the estimates of Davis (2011) and Hodge (2011): the former finds that the opening of fossil fuel plants in the US decreases housing prices by 4-7\% within 2 miles of the plants; the latter finds that ethanol plants in two communities in Michigan depressed the value of home units located within two miles of the plants by up to $18 \%$.

Note that the average change in prices between Period 2 and the base period is 1-2.2 percentage points higher than the change between Period 1 and the base period. A possible explanation for this relatively small difference is the seemly larger availability of new housing units in Period 2 relative to Period 1, as outlined in the previous section. While the relocation of the second power plant supposed an additional improvement in environmental quality, likely further shifting the demand upwards, by Period 2 there was a larger housing inventory of new apartment units compared to Period 1 (i.e. a larger shift in the supply curve). The estimation results on the volume of sales (discussed below) confirms a higher market dynamism in Period 2.

The control variables generally have the expected signs. For example, we observe a floor-level premium where the price of an apartment unit located one floor higher than another unit is on average $0.2-0.7 \%$ higher. Units built by a top developer are $8.5-12.3 \%$ more expensive than those built by other developers, likely reflecting a higher (actual or perceived) quality of the unit. Prices also seem to decrease as we move away from the city center, particularly for units located beyond the 1-h inner-city traffic circle.

\footnotetext{
44 The statistical significance of the results is not sensitive to alternatively clustering by district-quarter or district-year. Similarly, the results are generally not affected to only clustering by district using the wildbootstrap procedure proposed by Cameron et al. (2008) with 1000 replications. Further details are available upon request.

${ }^{45}$ Since we estimate log-linear models, we accordingly transform the coefficients reported in the table to express them as percentages in the text.
} 
Table 2 Difference-in-differences price estimations

\begin{tabular}{|c|c|c|c|}
\hline Variable & (1) Full sample & (2) Period 1 versus period 0 & (3) Period 2 versus period 0 \\
\hline \multicolumn{4}{|c|}{ Dependent variable: Ln price per square meter } \\
\hline If within $5 \mathrm{~km}$ of plants & $-0.047 * *(0.019)$ & $-0.021(0.015)$ & $-0.051 * *(0.020)$ \\
\hline If period 1 & $0.305 * * *(0.023)$ & $0.169 * * *(0.020)$ & \\
\hline $\begin{array}{l}\text { If within } 5 \mathrm{~km} \text { of plants* If } \\
\text { period } 1\end{array}$ & $0.114 * * *(0.024)$ & $0.122 * * *(0.021)$ & \\
\hline If Period 2 & $0.375^{* * * *}(0.029)$ & & $0.378 * * *(0.031)$ \\
\hline $\begin{array}{l}\text { If within } 5 \mathrm{~km} \text { of plants*If } \\
\text { period } 2\end{array}$ & $0.134 * * *(0.025)$ & & $0.131 * * *(0.026)$ \\
\hline $\begin{array}{l}\text { Unit size (00 s square } \\
\text { meters) }\end{array}$ & $0.031 * * *(0.011)$ & $0.028 *(0.015)$ & $0.040 * * *(0.011)$ \\
\hline Floor level & $0.003 * * *(0.000)$ & $0.007 * * *(0.001)$ & $0.002 * * *(0.000)$ \\
\hline If top developer & $0.109 * * *(0.012)$ & $0.082 * * *(0.012)$ & $0.116 * * *(0.015)$ \\
\hline If elevator in building & $0.017(0.016)$ & $0.012(0.017)$ & $0.032 *(0.017)$ \\
\hline $\begin{array}{l}\text { Located between circle } \\
\text { center-circle } 1\end{array}$ & $0.014(0.027)$ & $-0.034(0.021)$ & $0.017(0.030)$ \\
\hline $\begin{array}{l}\text { Located between circle } \\
\text { 1-circle } 2\end{array}$ & $-0.089 * * *(0.026)$ & $-0.121 * * *(0.019)$ & $-0.093 * * *(0.030)$ \\
\hline $\begin{array}{l}\text { Located between circle } \\
\text { 2-circle } 3\end{array}$ & $-0.207 * * *(0.027)$ & $-0.187 * * *(0.019)$ & $-0.220 * * *(0.031)$ \\
\hline Located outside circle 3 & $-0.334 * * *(0.031)$ & $-0.310 * * *(0.026)$ & $-0.349 * * *(0.035)$ \\
\hline Constant & $6.616 * * *(0.181)$ & $6.207 * * *(0.237)$ & $6.677 * * *(0.210)$ \\
\hline \#Observations & 361,936 & 164,089 & 288,238 \\
\hline R-squared & 0.431 & 0.374 & 0.451 \\
\hline
\end{tabular}

$* * *, * *, *$ Significant at $1 \%, 5 \%$ and $10 \%$ level. Robust standard errors reported in parentheses clustered by district and month. Period 0: January 2005 through June 2006; Period 1: August 2006 through May 2007; Period 2: July 2007 through May 2009. All regressions include controls at the district level (population density, per capita income and household size) and year-quarter fixed effects

Turning to the effect of the plants' closings on the volume of transactions, Table 3 presents the results of the DID weekly transactions model defined in Eq. (2). As in Table 2, the first column reports the estimation results using the full sample, while in the other two columns we separately compare Period 1 and Period 2 versus the base period. We find that the number of new apartment purchases considerably increased in the vicinity of the plants after their relocation, as opposed to the neighboring areas farther away, especially in Period 2. The weekly volume of transactions within five kilometers of the plants increased by an additional $13-17 \%$ between the base period and the period after the closing of Chengdu power plant, although the change is not statistically significant at conventional levels, and by $27-31 \%$ between the base period and the period after the closing of both Chengdu and Hua Neng power plants.

Regarding the effect of the plants' closings on the distribution of housing prices, Fig. 4 shows the estimated percentile treatment effects on prices defined in Eq. (4), resulting from the CIC estimation. Panel A presents the estimated effects when comparing Period 
Table 3 Difference-in-differences weekly volume of transactions estimations

\begin{tabular}{|c|c|c|c|}
\hline Variable & (1) Full sample & (2) Period 1 versus period 0 & (3) Period 2 versus period 0 \\
\hline \multicolumn{4}{|c|}{ Dependent variable: Ln weekly transactions per ring of one kilometer radius around plants } \\
\hline If within $5 \mathrm{~km}$ of plants & $-0.475 * * *(0.102)$ & $-0.505 * * *(0.110)$ & $-0.463 * * *(0.102)$ \\
\hline If period 1 & $0.281(0.207)$ & $0.264(0.232)$ & \\
\hline $\begin{array}{l}\text { If within } 5 \mathrm{~km} \text { of plants*If } \\
\text { period } 2\end{array}$ & $0.122(0.149)$ & $0.158(0.147)$ & \\
\hline If period 2 & $0.474 * *(0.207)$ & & $0.458 * *(0.210)$ \\
\hline $\begin{array}{l}\text { If within } 5 \mathrm{~km} \text { of plants*If } \\
\text { period } 2\end{array}$ & $0.273 * *(0.119)$ & & $0.236 * *(0.120)$ \\
\hline $\begin{array}{l}\text { Unit size (00 s square } \\
\text { meters) }\end{array}$ & $-0.454 * * *(0.130)$ & $-0.284 *(0.158)$ & $-0.363 * *(0.143)$ \\
\hline Floor level & $0.055 * * *(0.010)$ & $0.051 * * *(0.017)$ & $0.060 * * *(0.011)$ \\
\hline If top developer & $0.084(0.056)$ & $0.003(0.106)$ & $0.123 * *(0.059)$ \\
\hline If elevator in building & $0.516 * * *(0.121)$ & $0.494 * * *(0.122)$ & $0.516 * * *(0.124)$ \\
\hline $\begin{array}{l}\text { Located between circle } \\
\text { center-circle } 1\end{array}$ & $-1.024 * * *(0.244)$ & $-0.935^{* * *}(0.344)$ & $-1.026^{* * *}(0.245)$ \\
\hline $\begin{array}{l}\text { Located between circle } \\
\text { 1-circle } 2\end{array}$ & $-0.027(0.087)$ & $0.138(0.134)$ & $-0.031(0.095)$ \\
\hline $\begin{array}{l}\text { Located between circle } \\
\text { 2-circle } 3\end{array}$ & $0.206^{* * *}(0.049)$ & $0.293 * * *(0.072)$ & $0.180 * * *(0.053)$ \\
\hline Located outside circle 3 & $-0.011(0.068)$ & $-0.216^{*}(0.114)$ & $-0.020(0.075)$ \\
\hline Constant & $4.810 * * *(0.855)$ & $3.695 * *(1.459)$ & $4.739 * * *(0.950)$ \\
\hline \#Observations & 3246 & 1752 & 2616 \\
\hline R-squared & 0.258 & 0.204 & 0.290 \\
\hline
\end{tabular}

$* * *, * *, *$ Significant at $1 \%, 5 \%$ and $10 \%$ level. Robust standard errors reported in parentheses clustered by district and month. Period 0: January 2005 through June 2006; Period 1: August 2006 through May 2007; Period 2: July 2007 through May 2009. The housing characteristics included in the regressions are the corresponding median values of the units sold per week and for each ring of one kilometer radius around the power plants. All regressions include controls at the district level (population density, per capita income and household size) and year-quarter fixed effects

1 with the base period and Panel B when comparing Period 2 with the base period. ${ }^{46}$ The horizontal axis in the graphs represents the percentile of the price distribution, while the vertical axis is the estimate of the corresponding percentile treatment effect. The dashed lines are confidence bands of \pm 2 standard errors obtained by bootstrapping (based on 200 replications).

Several interesting patterns emerge from Fig. 4. First, the estimated effects are positive across all percentiles, both in Panel A and Panel B, which illustrates that the relocation of

\footnotetext{
46 Figure A.3 in Appendix A plots the observed and counterfactual density and cumulative distribution functions of housing prices within five kilometers of the plants after their relocation, constructed using the CIC method; Panel A corresponds to the period after the relocation of Chengdu power plant (August 2006May 2007) and Panel B to the period after the relocation of both Chengdu and Hua Neng power plants (July 2007-May 2009). It follows that there was a general increase in house prices within five kilometers after the plants' relocation: if the relocation events had not occurred, the distribution of housing prices would be leftskewed compared to the actual distribution pattern.
} 

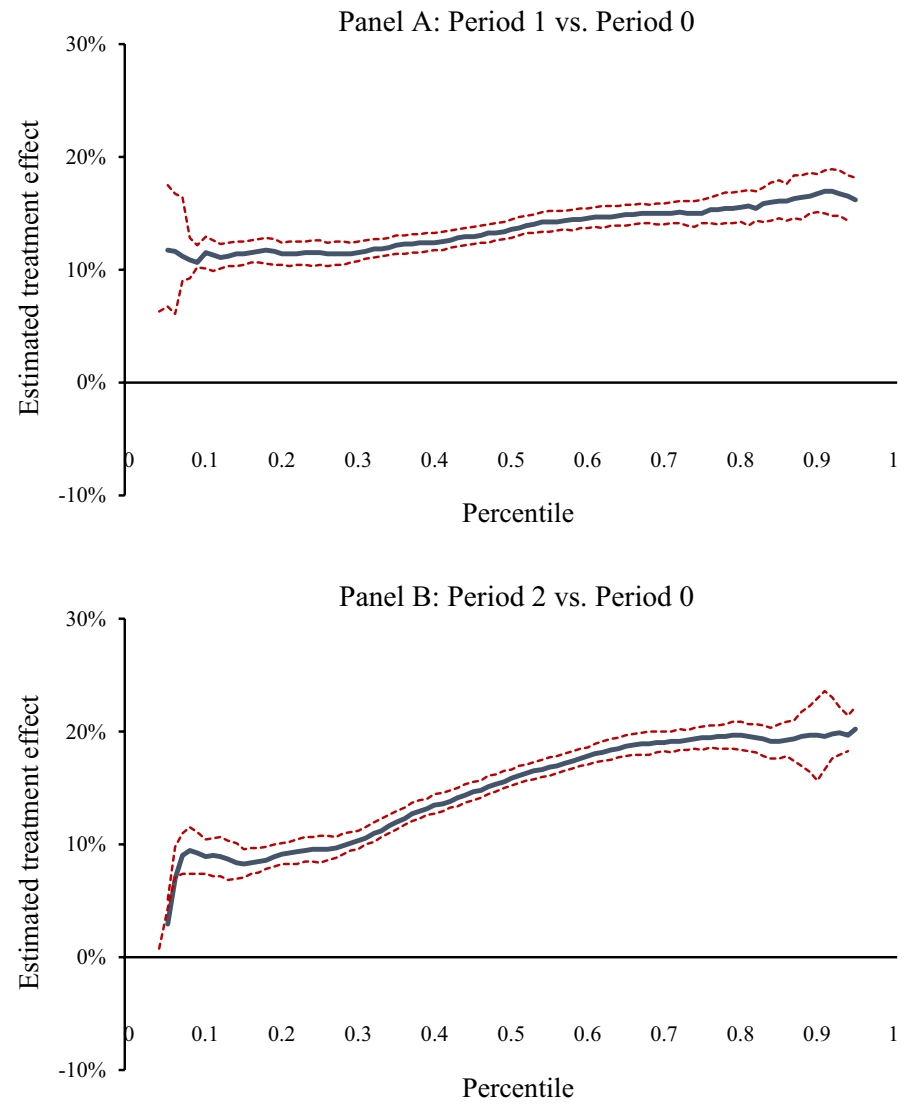

Fig. 4 Percentile treatment effects on prices based on change-in-changes estimation. Note: Period 0: January 2005 through June 2006; Period 1: August 2006 through May 2007; Period 2: July 2007 through May 2009. The dashed lines are confidence bands of \pm 2 standard errors resulting from 200 bootstrap replications

the power plants increased house prices within five kilometers along the entire price distribution. Second, the percentile treatment effect is an upward-sloping curve and the slope is steeper when comparing Period 2 with the base period than Period 1 with the base period. This suggests that higher priced houses in the vicinity of the plants experienced a higher increase in prices after the relocation of the power plants, and that the increase is sharper when comparing the period after the relocation of both plants with the base period. The corresponding treatment effects for the $25 \%, 50 \%$ and $75 \%$ percentiles are $9.6 \%, 15.8 \%$ and $19.4 \%$ when comparing the period after the relocation of the two power plants (Period 2) with the base period (Period 0), and $11.5 \%, 13.6 \%$ and $15 \%$ when comparing the period after the relocation of Chengdu plant (Period 1) with the base period.

Finally, as noted in the previous section, the assumption that any differences between groups (areas) is stable across time constitutes the basis for implementing a DID and CIC model, as the estimation of the trend in one group can assist in eliminating the trend in the other group (Athey and Imbens 2006). While alike variations in available socioeconomic (and housing) characteristics between the treatment and control area shown earlier provide some support to this assumption, it is worth noting that we also do not find evidence of 
different hedonic coefficients (for unit size, floor level, top developer and elevator) between the treatment and control group, before and after the relocations. ${ }^{47}$

In a similar vein, we recognize that the estimated effect of the plants' closings on the housing market may still be correlated with other unobservable factors besides a decrease in pollution. As indicated above, the closure of the plants could be associated with a decrease in other negative externalities such as noise and visual disamenities as well as a positive neighborhood externality and local features, including more modern apartment complexes. Hence, the estimated effect of the relocations does not necessarily represent, for example, the effect of air pollution on housing prices or a willingness to pay for air quality given the potential changes in other factors associated with the redevelopment of the area (relative to the rest of the downtown area). Kuminoff and Pope (2014) refer to this matter as the "conflation bias" when attempting to recover the willingness to pay for a public good, which is beyond the objective of this study due to data restrictions (see also Klaiber and Smith 2013; Muehlenbachs et al. 2015; Banzhaf 2015). ${ }^{48}$

\subsection{Matched sample}

While the analysis above focuses on comparable new apartment units located in the downtown area of the city, it is worth assessing the sensitivity of our results, particularly the DID and CIC price effects, to first pre-balancing our data. Following the discussion in Ho et al. (2007) and Johnston and Moeltner (2019), implementing a mixed approach, where we match treated and control units based on observable characteristics prior to the regression analysis, can help to better account for potential unobservable confounders. We accordingly pre-balance our data using one-to-one propensity score matching, with and without replacement, based on unit characteristics and location relative to the city center and imposing a common support and caliper. ${ }^{49}$ We also restrict the matching to pairing treated and control units that were both sold within the same period (i.e. whether before or after the relocation of the first or second plant) to avoid imbalance in both unobservable temporal effects and in pre- and post-relocation information between treated and control units (Kuminoff and Pope 2012; Johnston and Moeltner 2019).

Table A.2 in Appendix A shows that the matching process, whether with or without replacement, results in lower discrepancies between the treated and control units. Table 4 presents, in turn, the corresponding average effects of the plants' relocations on housing prices when restricting the DID analysis to the matched samples (Panel A with replacement

\footnotetext{
47 We estimated a more flexible price regression model than Eq. (1), allowing for the hedonic (housing) coefficients to vary both over time (before and after the relocations) and between the treatment and control area (within and beyond five kilometers around the plants). Further details are available upon request.

48 The estimated price effect can be translated into a marginal willingness to pay for environmental quality if the corresponding gradient of the hedonic price function remains constant over the period of study. Muehlenbachs et al. (2015) argue that if preferences are a function of residents' attributes and variations in socioeconomic characteristics are not correlated with variations in environmental quality, then the estimated difference-in-differences effect most likely reflects a willingness to pay. Banzhaf (2015), in turn, shows that the difference-in-differences estimate identifies the "average direct effect" on prices of a change in a public good (i.e. environmental quality); when omitted variables are present, this estimate recovers an unbiased lower bound estimate of welfare changes after a change in the public good.

49 The common support involves dropping treated units whose propensity score is higher than the maximum or less than the minimum score of the control units, while we impose a caliper (maximum score distance between a matched treated and control unit) of 0.001 ,
} 
Table 4 Estimated change in prices based on matched sample

\begin{tabular}{|c|c|c|c|}
\hline Variable & (1) Full sample & $\begin{array}{l}\text { (2) Period } 1 \text { versus } \\
\text { Period } 0\end{array}$ & $\begin{array}{l}\text { (3) Period } 2 \text { versus } \\
\text { Period } 0\end{array}$ \\
\hline
\end{tabular}

Panel A: Matched sample (with replacement)

$\begin{array}{lllc}\text { If within } 5 \mathrm{~km} \text { of plants*If Period 1 } & 12.0 \% * * * & 12.5 \% * * * \\ \text { If within 5 km of plants*If Period 2 } & 13.9 \% * * * & & 14.0 \% * * * \\ \text { \#Treated units } & 86,904 & 35,242 & 70,795 \\ \text { \#Control units } & 18,950 & 8168 & 15,295 \\ \text { Panel B: Matched sample (without replacement) } & & \\ \text { If within 5 km of plants*If period 1 } & 12.1 \% * * * & 12.5 \% * * * & 12.0 \% * * * \\ \text { If within 5 km of plants*If period 2 } & 12.2 \% * * * & & 68,164 \\ \text { \# Treated units } & 84,147 & 34,618 & 68,164 \\ \text { \# Control units } & 84,147 & 34,618 & \end{array}$

$* * *, * *, *$ Significant at 1\%,5\% and 10\% level. Panel A corresponds to one-to-one matched sample with replacement and Panel B to one-to-one matched sample without replacement. Matching using propensity score matching based on unit characteristics and location relative to the city center, imposing a common support and caliper of 0.001. Period 0: January 2005 through June 2006; Period 1: August 2006 through May 2007; Period 2: July 2007 through May 2009. Estimated percentage changes reported are based on the difference-in-differences regression coefficients reported in Table A.3 transformed by $100 \times(\exp ($ coefficient $)-1)$

and Panel B without replacement), where the regression controls for all the housing, location, district and time effects included in Eq. (1); the full estimation results are reported in Table A.3 in Appendix A. We find very similar results to those obtained using the full sample. In particular, we observe a price effect of $12-12.5 \%$ after the relocation of the first plant, and of $12-14 \%$ after the relocation of the second plant.

Likewise, the CIC results reported in Figure A.4 in Appendix A show an upward-sloping price effect along the price distribution, which is steeper when comparing Period 2 (i.e. after the relocation of the second plant) with base Period 0 than when comparing Period 1 (i.e. after the relocation of the first plant) with the base period. The treatment effects for the $25 \%, 50 \%$ and $75 \%$ percentiles are $5.7-6.6 \%, 13.9-15.8 \%$ and $16.6-19.2 \%$ between Period 2 and Period 0, and 9.9-10.4\%, 11.7-13\% and 14.1-15.2\% between Period 1 and Period 0. Overall, the results are robust to first pre-balancing the data.

\subsection{Additional estimations}

We now perform several additional estimations and robustness checks to further assess the validity of our results. ${ }^{50}$

\subsubsection{Excluding the closure announcement period}

Given that the first announcements of the plants' closures occurred towards the end of January 2006, we exclude from the base period the months of February through June

${ }^{50}$ Tables A.4-A.8 in Appendix A report the full estimation results of these additional robustness checks. 
Table 5 Estimated effect on prices based on additional estimations

Estimated effect on prices $\quad$ (1) Period $1 \quad$ (2) Period 2

versus Period 0 versus Period 0

Panel A: Base model

If within $5 \mathrm{~km}$ of plants

$12.1 \% * * * \quad 14.3 \% * * *$

Panel B: Excluding transactions of February-June 2006 from Period 0

If within $5 \mathrm{~km}$ of plants

$10.3 \% * * *$

$12.5 \% * * *$

Panel C: Including only buildings which started sales prior to the plant(s) relocation

If within $5 \mathrm{~km}$ of plants

$10.1 \% * * *$

$7.0 \% * * *$

Panel D: Alternative comparison group 5-10 km

If within $5 \mathrm{~km}$ of plants

$14.6 \% * * * \quad 15.4 \% * * *$

Panel E: Alternative model using distance bins of $2.5 \mathrm{~km}$ (base category distance bin: more than $12.5 \mathrm{~km}$ )

If within $0-2.5 \mathrm{~km}$ of plants

$20.4 \% * * * \quad 28.3 \% * * *$

If within $2.5-5 \mathrm{~km}$ of plants

$20.3 \% * * * \quad 31.8 \% * * *$

If within $5-7.5 \mathrm{~km}$ of plants

$7.3 \%$

$18.5 \% * * *$

If within $7.5-10 \mathrm{~km}$ of plants

$2.4 \%$

$11.6 \% * *$

If within $10-12.5 \mathrm{~km}$ of plants

$2.7 \%$

$6.5 \% * * *$

Panel F: Alternative model accounting for location and wind direction

If within $5 \mathrm{~km}$ of plants and southwest of plants

$15.0 \% * * * \quad 23.2 \% * * *$

If within $5 \mathrm{~km}$ of plants but not southwest of plants

$9.9 \% * * * \quad 10.1 \% * * *$

$* * *, * *$, * Significant at 1\%, 5\% and 10\% level. Period 0: January 2005 through June 2006; Period 1: August 2006 through May 2007; Period 2: July 2007 through May 2009. Estimated percentage changes reported are based on the difference-in-differences regression coefficients reported in Tables 2, A.4, A.5, A.6, A.7 and A. 8 transformed by $100 \times(\exp ($ coefficient $)-1)$

2006 since these announcements could also have introduced some noise over the following months prior to the closing. In addition, it is possible that developers (and consumers) started to adjust their selling (buying) behavior after these announcements, provided that most of the new house transactions in China are made through forward contracts. In this scenario, the results reported above could underestimate the effect of the plants' closures on the housing market.

Panel B of Table 5 reports the average effects on prices when restricting the base period. We find though a smaller effect on prices than in the base results. In particular, we observe a $10.3 \%$ increase in the price per square meter after the closing of Chengdu plant and a $12.5 \%$ increase after the closing of both plants, roughly 1.7-1.8 percentage points smaller increase in prices than in the base model (reported in Panel A of Table 5 for ease of comparison). The results do not support the notion that prices started to adjust upwards prior to the plants' closure. ${ }^{51}$ In fact, in the first months following the official announcement of the closures (February through April 2006) we observe a decrease in average prices within

\footnotetext{
51 We also find a lower effect on prices when alternatively including February-June 2006 as part of treatment Period 1.
} 
five kilometers of the plants, as opposed to prices in the rest of the downtown area (see also Panel A in Fig. 3). ${ }^{52}$

\subsubsection{Including only buildings under construction prior to relocations}

Second, we re-estimate the price model considering only units in buildings that were under construction prior to each of the plants' relocation. The improvement of the environmental quality near the plants after their relocation, may both directly increased the price of buildings already under construction as well as promoted the construction of relatively more upscale residential complexes with different amenities and features (unobserved to us), further raising average housing prices in the area. Hence, to (partially) isolate the first direct effect on prices from the second indirect effect, we compare changes in prices between Period 1 and the base period considering only units in buildings under construction prior to Period 1, and compare changes in prices between Period 2 and the base period considering only units in buildings under construction prior to Period $2 .{ }^{53}$ We determine whether a building was already under construction prior to the plants' relocations based on the date when developers where allowed to start selling units in the building.

Panel $\mathrm{C}$ of Table 5 shows the corresponding average change in prices. We find that prices increased by an additional $10.1 \%$ after the relocation of Chengdu power plant and by $7 \%$ after the relocation of Hua Neng plant. Thus, when only considering units already under construction prior to the relocations, we still observe a significant positive direct effect on prices. The observed changes further suggest that the plants' relocation seemed to have had a higher direct than indirect effect on housing prices in Period 1.

\subsubsection{Alternative comparison group}

We evaluate the sensitivity of our results when limiting the comparison group to 5-10 km away of the power plants. Similar to the matching exercise at the unit level performed in the previous section, we would expect downtown areas closer to the treatment area to be more comparable than areas farther away. We accordingly re-estimate the model described in Eq. (1) where the treatment group are units located within five kilometers of the plants and the control group are units located 5-10 km away of the plants.

Panel D of Table 5 presents the estimation results. We find a $14.6 \%$ increase in prices after the closing of Chengdu plant and a $15.4 \%$ increase after the closing of the second plant. Hence, we find similar statistically significant effects when considering this alternative comparison group that support our base results.

\footnotetext{
52 Per our conversations with local real estate agents, when sales in a new building start in the city, typically units with better attributes are the first to sell out. It could be the case that in the immediate months after the announcement, all vacant (readily available) new units in the areas closer to the plants, including several units with relatively fewer attributes (and lower pre-established prices) were rapidly sold out, which could explain this temporal price decrease while other new buildings continued to be constructed. We similarly observe an increase in the weekly volume of transactions in the area in February through April 2006 (see Panel B of Fig. 3) and a slightly increase, for example, in the share of units sold in lower floors and of smaller size (i.e. cheaper units), although we recognize that we cannot be conclusive about this hypothesis.

53 Most buildings under construction in base Period 0 were sold by the end of Period 1 . Hence, for the comparison between Period 2 and the base period, we include buildings which started to be constructed after the relocation of the first plant and exclude those which started to be constructed after the relocation of the second plant, thereby partially isolating the first direct effect from the second effect described above.
} 


\subsubsection{Alternative model specification with multiple distance bins}

We also assess the sensitivity of our results when considering an alternative model specification with different distance bins to the power plants. If the plants' relocation and consequent environment improvement is driving the increase in house prices, we would expect a higher increase in prices in areas closer to the plants compared to areas located farther away. We re-estimate the price model defined in Eq. (1) with distance bins of 0-2.5, 2.5-5, 5-7.5, 7.5-10 and 10-12.5 km from the plants (base category is more than $12.5 \mathrm{~km}$ ).

Panel E of Table 5 reports the estimation results using this alternative model. We observe a larger effect on prices among units located closer to the plants, particularly for units located 0-2.5 and 2.5-5 km from the plants, and the effect decreases as we move farther away, especially in Period 2. In Period 1, prices increased by $20.4 \%$ and $20.3 \%$ among units located 0-2.5 and 2.5-5 km from the plants, compared to units located more than $12.5 \mathrm{~km}$ away; while units located 5 through $12.5 \mathrm{~km}$ also show a positive relative increase in prices, the change is not statistically significant. In period 2, prices increased by $28.3 \%, 31.8 \%$, $18.5 \%, 11.6 \%$ and $6.5 \%$, respectively across the different distance bins considered. Note also that the price changes are not statistically different between units located $0-2.5 \mathrm{~km}$ and $2.5-5 \mathrm{~km}$, which together form part of the treatment group in the base analysis. ${ }^{54}$

\subsubsection{Alternative model specification accounting for wind direction}

Given that the wind blows southwest in Chengdu, we evaluate whether nearby units located southwest to the power plants show a higher increase in prices. As discussed above, while the observed change in prices could still be explained by factors other than a decrease in pollution, if improved air quality is one of the main factors, we would then expect a higher price increase among these units.

Panel $\mathrm{F}$ of Table 5 shows that nearby units located downwind to the plants effectively exhibit a higher increase in prices than the other nearby units. In particular, units located within five kilometers and southwest of the plants report a $15 \%$ increase in prices after the relocation of the first plant (Period 1) and a 23.2\% increase in prices after the relocation of the second plant (Period 2), while other units located within five kilometers of the plant report a $9.9 \%$ and $10.1 \%$ increase in prices. ${ }^{55}$ In sum, all these robustness checks provide additional support to our main findings.

\subsection{Estimated aggregate effect of the plants' relocation on the local housing market}

We can perform some back-of-the-envelope calculations to put our results in perspective. The estimation results can be used to approximate the aggregate effect of the plants'

\footnotetext{
$\overline{54}$ We also separately considered a treatment threshold radius of $2.5 \mathrm{~km}$ as well as a threshold radius of $7.5 \mathrm{~km}$. We find somewhat similar effects on prices when considering a shorter distance than the base model of five kilometers and a lower effect when considering a larger distance, which also supports the choice of the five-kilometer circle. In the case of a radius of $2.5 \mathrm{~km}$ around the plants, prices increased by $12-15 \%$, while in the case of a radius of $7.5 \mathrm{~km}$, prices increased by around $5 \%$. Additional details are available upon request.

55 When segmenting the sample though to separate compare Period 1 versus Period 0 and Period 2 versus Period 0 , the change in prices in Period 1 is not statistically different between nearby units located southwest of the plants and other nearby units (see Table A.8 in Appendix A).
} 
relocation on the market for new apartment units in neighborhoods surrounding the power plants. According to the DID estimates (Table 2), the price per square meter in the area increased by $12.1 \%$ during the period following the closing of Chengdu power plant (Period 1), and by $14.3 \%$ during the period following the closing of both Chengdu and Hua Neng plants (Period 2). Similarly, the number of new units sold increased by $13 \%$ and $31.4 \%$, respectively (Table 3). We can then calculate the combined effect of the plants' closings as,

$$
V_{s, D I D}=\left[\left(p_{s}-\frac{p_{s}}{1+\Delta p_{s} / p_{0}}\right) \frac{q_{s}}{1+\Delta q_{s} / q_{0}}+p_{s}\left(q_{s}-\frac{q_{s}}{1+\Delta q_{s} / q_{0}}\right)\right] a_{s}
$$

where $p_{s}$ is the observed average price per square meter within five kilometers of the plants in period $s, s=1,2, q_{s}$ is the total number of new housing transactions, $a_{s}$ is the average size of an apartment unit in square meters, and $\Delta p_{s}$ and $\Delta q_{s}$ are the estimated absolute changes in prices and volume of transactions. The first term of Eq. (5) captures the increase in prices of the projected number of unit purchases in the absence of the plants' closures, while the second term corresponds to the value of the additional unit purchases resulting from the plants' closures. Note that an implicit assumption in this calculation is that the relocations did not have major effects beyond five kilometers of the plants. ${ }^{56}$

Likewise, we can obtain an alternative measure by using the CIC estimation results (Fig. 4), which permit to account for varying price changes along the housing price distribution (by percentile). We can divide all transactions that occurred after the relocation events into each corresponding percentile group based on the price of the apartment unit, and derive the aggregate effect of the plants' closings as,

$$
V_{s, C I C}=\sum_{i=1}^{99}\left[\left(p_{s, i}-\frac{p_{s, i}}{1+\Delta p_{s, i} / p_{0, i}}\right) \frac{q_{s, i}}{1+\Delta q_{s} / q_{0}}+p_{s, i}\left(q_{s}-\frac{q_{s, i}}{1+\Delta q_{s} / q_{0}}\right)\right] a_{s, i}
$$

where $p_{s, i}, q_{s, i}$, and $a_{s, i}$ are the corresponding average price, transaction volume and average unit size in period $s$ and percentile $i$, and $\Delta p_{s, i}$ is the estimated absolute change in prices for percentile $i .^{57}$

As reported in Table 6, the estimated cumulative effect of the plants' closings on the housing market for new units is very similar using both methods. The monthly aggregate effect of the closures within five kilometers of the plants is 158-160 million RMB (21 million US dollars) over the 10 months after the relocation of Chengdu plant and 394-398 million RMB (52 million US dollars) over the 23 months after the relocation of both Chengdu and Hua Neng plants. These results are not negligible compared to the building costs of a coal-burning power plant of similar capacity to the two relocated plants (325 megawatts), but much less polluting and more efficient, which is around 650 million US dollars. ${ }^{58}$ The results are also not small compared to the findings of Davis (2011) for the

\footnotetext{
56 We further assessed this assumption by estimating an alternative price model with separate one-kilometer distance bins, and we do not find statistically significant effects after five kilometers (details available upon request). This finding is also in line with the DID results obtained in Sect. 4.4.3 where we restrict the comparison group to units located 5-10 km of the plants and we obtain similar price effects to our base model.

57 Since we do not estimate a CIC model for the weekly volume of transactions, we simply use the estimated DID change. The underlying assumption is that house purchases increased in the same proportion along the price distribution.

58 Chengdu power plant had a capacity of $125,000 \mathrm{~kW}$ and Hua Neng plant of $200,000 \mathrm{~kW}$. The cost estimate is based on a building cost of 2000 US dollars per kilowatt of capacity; the estimate excludes the electricity transmission costs of relocating the power plant farther away from the city, which are, for example, around 800 thousand US dollars per mile in the US (Hirst and Kirby 2002).
} 
Table 6 Estimated monthly aggregate effect of the plants' relocation on the housing market within five kilometers of power plants

\begin{tabular}{lll}
\hline Period & \multicolumn{2}{l}{ Value (Million yuan) per month } \\
\cline { 2 - 3 } & DID approach & CIC approach \\
\hline $\begin{array}{l}\text { After closing of Chengdu plant } \\
\text { (August 2006-May 2007) }\end{array}$ & 160 & 158 \\
$\begin{array}{l}\text { After closing of Chengdu and } \\
\text { Hua Neng plants (July 2007- } \\
\text { May 2009) }\end{array}$ & 398 & 394 \\
\hline
\end{tabular}

Calculations based on the estimated treatment effects on prices and volume of transactions from the difference-in-differences (DID) and change-in-changes (CIC) models

US, who estimates an average housing market capitalization of 13.2 million US dollars within 2 miles of the location of a power plant, although plants in the US are generally located in low population density areas. ${ }^{59}$

The estimated aggregate effect should still be interpreted with caution and as a reference estimate. First, the calculation accounts for both an increase in prices and volume of transactions over a relatively short period of time. While the housing market continues to rapidly grow in Chengdu, particularly in the downtown area, at a certain point the housing supply (and demand) will start growing at a slower rate due to space constraints; in the long term, we will have a perfectly inelastic housing supply, although we could still have parallel shifts in demand. Second, the analysis does not account for the effect on prices of old housing units as detailed supply data of all properties in the area are not available (i.e. the estimated effect underestimates the potential impact on all residential properties). ${ }^{60}$ In addition, the analysis excludes the impact on commercial and industrial properties.

\section{Concluding Remarks}

Air pollution is a major environmental problem in China, which has caused widespread health and ecological issues. Part of the government plans to reduce air pollution involves the closure and relocation of high polluting and energy-consuming power plants, in a context where still most of the energy production in the country is based on traditional, nonrenewable fossil fuel energy sources. This paper examines the effect of the closing of the two major, outdated power plants in downtown Chengdu on the housing market in the surrounding areas. We use a unique and extensive transaction dataset of new apartment units.

The estimation results indicate a significant impact of the plants' closings on housing prices and volume of transactions. In particular, the closing of the power plants is associated with a $12-14 \%$ rise in prices within five kilometers of the plants, relative to comparable neighborhoods located farther away, and a $13-31 \%$ increase in the number of new apartment purchases. We also find that more expensive apartment units experienced a

\footnotetext{
59 Davis' calculations are based on a perfectly inelastic housing supply as his analysis focuses on existing housing units in the vicinity of power plants while we focus on new apartment units.

${ }^{60}$ It is worth noting that the housing market in Chengdu, as well as the rest of China, is relatively new as the Chinese housing market reform started in 1998. As indicated earlier, around $26 \%$ of the total housing area in Chengdu was occupied by second-hand units during the period of the study.
} 
higher increase in prices. Additional estimations support the positive effect of the relocations on the local housing market, including a larger impact when considering areas closer to the plants and the opposite when considering areas farther away. On aggregate, we find non-negligible effects of the closures on the housing market for new apartment units.

The results obtained contribute to the ongoing discussion in China about the potential benefits of relocating and constructing new power plants near industrial and densely populated urban areas. Besides the natural benefits of moving to alternative, more efficient energy production and dust removal technologies, this study shows that the plants' relocation had an important positive impact on the local housing market. To the extent that the valuation of environmental quality is a function of the current level of pollution in an area, we might expect significant effects from old plants' relocations on the housing market of other highly polluted Chinese cities.

Finally, since we rely on a before-after comparison across different neighboring areas, we acknowledge that there could still be potential unobservable differences not accounted for that could be influencing our results, although the relatively short period of the analysis around the plants' closures contribute to reduce this possibility. Similarly, the estimated effects on the housing market are not necessarily fully explained by an improvement in the environmental quality of the area but may also be correlated with other supply- and demand-driven factors associated with the redevelopment and improvement of the area. Future research should attempt to further quantify the potential short- and long-term effects of power plants' closures on local markets, especially in a setting like China with very high levels of pollution, an increasing demand for low-cost energy plants, and with a limited number of related cost-benefit studies. As more data become available, the studies should not only be restricted to measuring direct effects on particular markets but also more general effects on, for example, the labor supply and economic activity (see, eg, Hanna and Oliva 2015).

Open Access This article is licensed under a Creative Commons Attribution 4.0 International License, which permits use, sharing, adaptation, distribution and reproduction in any medium or format, as long as you give appropriate credit to the original author(s) and the source, provide a link to the Creative Commons licence, and indicate if changes were made. The images or other third party material in this article are included in the article's Creative Commons licence, unless indicated otherwise in a credit line to the material. If material is not included in the article's Creative Commons licence and your intended use is not permitted by statutory regulation or exceeds the permitted use, you will need to obtain permission directly from the copyright holder. To view a copy of this licence, visit http://creativecommons.org/licenses/by/4.0/.

\section{References}

Abadie A (2005) Semiparametric difference-in-differences estimators. Rev Econ Stud 72(1):1-19

Abott JK, Klaiber A (2011) An embarassment of riches: confronting omitted variable bias and multiscale capitalization in hedonic price models. Rev Econ Stat 93(4):1331-1342

Ames MR, Zemba SG, Yamartino RJ, Valberg PA, Green LC (2002) Comments on: Using CALPUFF to evaluate the impacts of power plant emissions in Illinois: model sensitivity and implications. Atmos Environ 36:2263-2265

Ashenfelter O, Card D (1985) Using the longitudinal structure of earnings to estimate the effects of training programs. Rev Econ Stat 67(4):648-660

Athey S, Imbens G (2006) Identification and inference in nonlinear difference-in-differences models. Econometrica 74(2):431-497

Bajari P, Benkard CL (2005) Demand estimation with heterogeneous consumers and unobserved product characteristics: a hedonic approach. J Polit Econ 113(6):1239-1276 
Banzhaf HS (2015) Panel data hedonics: Rosen's first stage and difference-in-differences as "sufficient statistics." Georgia State University, Mimeo

Barwick PJ, Li S, Rao D, Zahur NB (2018) The morbidity cost of air pollution: Evidence from consumer spending in China. NBER working paper 24688

Barwick PJ, Li S, Lin L, Zou E (2019) From fog to smog: the value of pollution information. Cornell University, Mimeo

Bayer P, Keohane N, Timmins C (2009) Migration and hedonic valuation: the case of air quality. J Environ Econ Manag 58(1):1-14

Benson ED, Hansen JL, Schwartz AL Jr, Smersh GT (1998) Pricing residential amenities: the value of a view. J Real Estate Finance Econ 16:55-73

Blomquist GC (1974) The effect of electric utility power plant location on area property value. Land Econ 50(1):97-100

Cai F, Du Y, Wang MY (2008) The political economy of emissions in China: will low carbon-emissions growth be incentive compatible in the next decade and beyond? Econ Res 6:4-11 ((In Chinese))

Cameron AC, Gelbach J, Miller D (2008) Bootstrap-based improvements for inference with clustered errors. Rev Econ Stat 90(3):414-427

Chau K, Wong S, Yiu C (2004) The value of the provision of a balcony in apartments in Hong Kong. Prop Manag 22(3):250-264

Chay KY, Greenstone M (2005) Does air quality matter? Evidence from the housing market. J Polit Econ 113(2):376-424

Chen SY (2009) Energy consumption, carbon dioxide emission and sustainable development of the Chinese industry. Econ Res 4:41-55 ((In Chinese))

Chen Y, Ebenstein A, Greenstone M, Li H (2013) Evidence on the impact of sustained exposure to air pollution on life expectancy from China's Huai River policy. Proc Natl Acad Sci 110(32):12936-12941

Chengdu Municipal Government (2006) The eleventh five-year plan for national economic and social development of Chengdu. Chengdu Econ Dev 2:2-35 ((In Chinese))

Davis LW (2004) The effect of health risk on housing values: evidence from a cancer cluster. Am Econ Rev 94(5):1693-1704

Davis LW (2011) The effect of power plants on local housing values and rents. Rev Econ Stat 93(4):1391-1402

Epple D, Platt GJ (1998) Equilibrium and local redistribution in an urban economy when households differ in both preferences and incomes. J Urban Econ 43(1):23-51

Freeman M (2003) The measurement of enviromental and resource values: theory and Method. Resources for the Future, Washington DC

Gamble HB, Downing RH (1982) Effects of nuclear power plants on residential property values. J Reg Sci 22(4):457-478

Gamper-Rabindran S, Timmins C (2013) Does cleanup of hazardous waste sites raise housing values? Evidence of spatially localized benefits. J Environ Econ Manag 65(3):345-360

Ghanem D, Zhang J (2014) Effortless perfection: do Chinese cities manipulate air pollution data? J Environ Econ Manag 68(2):203-225

Glaeser EL, Gyourko J, Saks R (2005) Why is Manhattan so expensive? Regulation and the rise in housing prices. J Law Econ 48(2):331-369

Greenstone M, Gallagher J (2008) Does hazardous waste matter? Evidence from the housing market and the superfund program. Quart J Econ 123(3):951-1003

Hanna R, Oliva P (2015) The effect of pollution on labor supply: Evidence from a natural expirement in Mexico city. J Public Econ 122:68-79

Hirst E, Kirby B (2002) Transmission planning and the need for new capacity. US Department of Energy, Washington DC

Ho DE, Imai K, King G, Stuart EA (2007) Matching as nonparametric preprocessing for reducing model dependence in parametric causal inference. Polit Anal 15:199-236

Hodge TR (2011) The effect of ethanol plants on residential property values: evidence from Michigan. J Reg Anal Policy 41(2):148-167

Jim CY, Chen WY (2007) Consumption preferences and environmental externalities: a hedonic analysis of the housing market in Guangzhou. Geoforum 38(2):414-431

Johnston RJ, Moeltner K (2019) Special flood hazard effects on coastal and interior home values: one size does not fit all. Environ Resour Econ 74:181-210

Klaiber HA, Smith VK (2013) Quasi experiments, hedonic models, and estimating trade-offs for local amenities. Land Econ 89(3):413-431

Kong F, Wu D, Ma J (2008) The housing types in Western developed countries and the adjusting of housing supply structure in China. J Shenyang Jianzhu Univ (Social Science) 10:170-173 ((In Chinese)) 
Kuminoff NV, Pope JC (2012) A novel approach to identifying hedonic demand parameters. Econ Lett 116:374-376

Kuminoff NV, Pope JC (2014) Do “capitalization effects" for public goods reveal the public's willingness to pay? Int Econ Rev 55(4):1227-1250

Levy JI, Spengler JD, Hlinka D, Sullivan D (2000) Estimated public health impacts of criteria pollutant air emission from nine fossil-fueled power plants in Illinois. Mimeo Harvard School of Public Health, Department of Environmental Health, Boston, MA

Levy JI, Spengler JD, Hlinka D, Sullivan D, Moon D (2002) Using CALPUFF to evaluate the impacts of power plants emissions in Illinois: model sensitivity and implications. Atmos Environ 36:1063-1075

Li S, Liu Y, Purevjav A, Yang L (2019) Does subway expansion improve air quality? J Environ Econ Manag 96:213-235

Lin X, Elder M (2014) Major developments in China's national air pollution policies in the early 12th fiveyear plan period. Institute for global environmental strategies, Policy report no. 2013-02, Kanagawa, Japan

Lin BQ, Liu XY (2010) China's carbon dioxide emissions during the urbanization process: influence factors and reduction policies. Econ Res 8:66-78 ((In Chinese))

McCluskey JJ, Rausser GC (2003) Stigmatized asset value: is it temporary or long-term? Rev Econ Stat 85(2):276-285

Muehlenbachs L, Spiller E, Timmins C (2015) The housing market impacts of shale gas development. Am Econ Rev 105(12):3633-3659

Nelson JP (1981) Three mile island and residential property values: empirical analysis and policy implications. Land Econ 57(3):363-372

Rosen S (1974) Hedonic prices and implicit markets: product differentiation in pure competition. J Polit Econ 82(1):34-55

Schlenker W, Walker WR (2016) Airports, air pollution and contemporaneous health. Rev Econ Stud 83(2):768-809

Tu ZG (2008) Environment, resources and the coordination of industrial growth. Econ Res 2:93-104 ((In Chinese))

Viard VB, Fu S (2015) The effect of Beijing's driving restrictions on pollution and economic activity. J Public Econ 125:98-115

World Health Organization (WHO) (2014) Ambient Air Pollution database, https://www.who.int/phe/healt h_topics/outdoorair/databases/cities/en/

Zhang X, Zhang X, Chen X (2017) Happiness in the air: How does a dirty sky affect mental health and subjective well-being? J Environ Econ Manag 85:81-94

Zheng S, Kahn ME (2008) Land and residential property markets in a booming economy: new evidence from Beijing. J Urban Econ 63:743-757

Publisher's Note Springer Nature remains neutral with regard to jurisdictional claims in published maps and institutional affiliations. 